\title{
COVID-19 and neuroinflammation: a literature review of relevant neuroimaging and CSF markers in central nervous system inflammatory disorders from SARS-COV2
}

\author{
Shitiz Sriwastava ${ }^{1,2,10}$ (1) $\cdot$ Medha Tandon ${ }^{3} \cdot$ Sanjiti Podury $^{4} \cdot$ Apoorv Prasad $^{5} \cdot$ Sijin Wen $^{6} \cdot$ Garret Guthrie $^{6}$. \\ Mihir Kakara $^{7} \cdot$ Shruti Jaiswal $^{2} \cdot$ Roshan Subedi $^{8} \cdot$ Mahmoud Elkhooly $^{9} \cdot$ Robert P. Lisak $^{10,11}$
}

Received: 3 April 2021 / Accepted: 10 May 2021 / Published online: 19 May 2021

(c) Springer-Verlag GmbH Germany, part of Springer Nature 2021

\begin{abstract}
Background The literature on neurological manifestations in COVID-19 patients has been rapidly increasing with the pandemic. However, data on CNS inflammatory disorders in COVID-19 are still evolving. We performed a literature review of CNS inflammatory disorders associated with coronavirus disease-2019 (COVID-19).

Methods We screened all articles resulting from a search of PubMed, Google Scholar and Scopus, using the keywords; "SARS-CoV-2 and neurological complication", "SARS-CoV-2 and CNS Complication" looking for reports of transverse myelitis, longitudinally extensive transverse myelitis, neuromyelitis optica, myelitis, Myelin Oligodendrocyte Glycoprotein Antibody Disorder (MOGAD), Acute Disseminated Encephalomyelitis (ADEM), Acute Hemorrhagic Necrotizing Encephalitis/Acute Hemorrhagic Leukoencephalitis (AHNE/AHLE), Cytotoxic lesion of the Corpus Callosum/Mild Encephalopathy Reversible Splenium Lesion(CLOCC/MERS) and Optic neuritis published between December 01, 2019 and March 15, 2021. Results Our literature search revealed 43 patients meeting the diagnosis of myelitis, including Transverse Myelitis, ADEM, AHNE/AHLE or CLOCC/MERS and Optic neuritis. Acute myelitis was most commonly associated with non-severe COVID19 and all reported cases of AHNE/AHLE had severe COVID-19 infection. Based on IDSA/ATS criteria of either requiring vasopressor for septic shock or mechanical ventilation, $49 \%(n=18)$ patients were considered to have a severe COVID infection. There were $7(n=19 \%)$ fatalities.

Conclusion To our knowledge, this is among the first reviews that includes the clinical features, neuroimaging, CSF findings and outcomes in COVID-19-associated CNS inflammatory disorders. Our observational review study reveals that although rare, myelitis, ADEM, AHNE and CLOCC can be associated with COVID-19 infection. Further studies using MRI imaging and CSF analysis in early diagnosis and intervention of these disorders are warranted.
\end{abstract}

Keywords COVID-19 $\cdot$ SARS-CoV-2 $\cdot$ ADEM $\cdot$ AHNE $\cdot$ Myelitis

Shitiz Sriwastava

Shitiz.sriwastava@hsc.wvu.edu

1 Department of Neurology, Rockefeller Neuroscience Institute, West Virginia University School of Medicine, Morgantown, WV 26506, USA

2 West Virginia Clinical and Translational Science Institute, Morgantown, WV, USA

3 Deaprtment of Neurology, University of Pittsburgh Medical Center, Pittsburgh, PA, USA

4 Army College of Medical Sciences, New Delhi, India

5 Department of Neurology, Berkeley Medical Center, West Virginia University, Martinsburg, WV, USA
6 Department of Biostatistics, West Virginia University, Morgantown, WV, USA

7 Department of Neurology, University of Pennsylvania, Philadelphia, PA, USA

8 Nepal Health Research Council, Kathmandu, Nepal

9 Department of Neuropsychiatry, Minia University, Minia, Egypt

10 Department of Neurology, Wayne State University, Detroit, MI, USA

11 Department of Biochemistry, Microbiology and Immunology, Wayne State University, Detroit, MI, USA 


\begin{tabular}{|c|c|}
\hline \multicolumn{2}{|l|}{ Abbreviations } \\
\hline COVID-19 & Coronavirus infectious disease-2019 \\
\hline $\mathrm{nCov}$ & Novel coronavirus \\
\hline SARS-CoV-2 & $\begin{array}{l}\text { Severe acute respiratory distress } \\
\text { syndrome coronavirus } 2\end{array}$ \\
\hline MERS & Middle-east respiratory syndrome \\
\hline Cerebrospinal fluid & CSF \\
\hline CNS & Central nervous system \\
\hline PNS & Peripheral nervous system \\
\hline RT-PCR & $\begin{array}{l}\text { Reverse transcription polymerase } \\
\text { chain reaction }\end{array}$ \\
\hline IDSA/ATS & $\begin{array}{l}\text { Infectious Diseases Society of } \\
\text { America/American Thoracic Society }\end{array}$ \\
\hline AHNE & $\begin{array}{l}\text { Acute hemorrhagic necrotizing } \\
\text { encephalitis }\end{array}$ \\
\hline AHLE & $\begin{array}{l}\text { Acute hemorrhagic } \\
\text { leukoencephalitis }\end{array}$ \\
\hline ADEM & $\begin{array}{l}\text { Acute disseminated } \\
\text { encephalomyelitis }\end{array}$ \\
\hline LETM & $\begin{array}{l}\text { Longitudinal extensive transverse } \\
\text { myelitis }\end{array}$ \\
\hline MRI & Magnetic resonance imaging \\
\hline CIS & Clinical isolated syndrome \\
\hline CLOCC & $\begin{array}{l}\text { Cytotoxic lesion of the corpus } \\
\text { callosum }\end{array}$ \\
\hline MOG & Myelin oligodendrocyte glycoprotein \\
\hline MERS & $\begin{array}{l}\text { Mild encephalopathy reversible } \\
\text { splenium lesion }\end{array}$ \\
\hline MOG & Myelin oligodendrocyte glycoprotein \\
\hline MOGAD & $\begin{array}{l}\text { Myelin oligodendrocyte glycoprotein } \\
\text { antibody disorder }\end{array}$ \\
\hline NMO & Neuromyelitis optica \\
\hline AQP4 & Aquaporin 4 \\
\hline IVIG & Intravenous immunoglobulin \\
\hline PLEX & Plasma exchange/plasmapheresis \\
\hline IVMP & Intravenous methylprednisolone \\
\hline $\mathrm{Hcq}$ & Hydroxychloroquine \\
\hline
\end{tabular}

\section{Introduction}

The worldwide dashboard of WHO registered more than 97 million confirmed cases and 2.1 million deaths due to COVID-19 as of January 24, 2021, a year after very first identified case [1]. Though it most often presents with symptoms and complications referable the respiratory system, reports of neurological manifestations continue to grow.

Several studies have reported neurological complications patients with COVID-19 [2-4]. Reports from Wuhan, China describe neurological complications frequently in patients with COVID-19. Those studies showed that $36.4 \%$ patients had neurological symptoms including acute cerebrovascular events, impaired consciousness and dizziness [4]. Another study showed one-third of patients with COVID-19 had neurological complications [5]. Anosmia and dysgeusia are also common neurological manifestation of COVID patients and is thought to be mediated by viral invasion of the olfactory neuroepithelium and cellular distribution of taste cells via ACE2 receptor [6, 7].

A prospective study by Frontera et al., detected neurologic disorders in $13.5 \%$ of patients with COVID-19 and indicated that neurological symptoms were associated with decreased likelihood of discharge to home and increased risk of in-hospial mortality [8]. These manifestations appear to be an amalgamation of systemic disease complications including systemic inflammatory mediators, nervous system and vasculature inflammation, or the effects of direct viral invasion. The neuroinflammation associated with COVID19 could be either from direct viral neuroinvasion leading to inflammation and cytokine release or from delayed autoimmune dysregulation or molecular mimicry leading to autoimmune/inflammatory syndromes that is parainfectious/ postinfectious [9-11]. Currently, there is insufficient knowledge about the effects of SARS-CoV-2 on central nervous system (CNS) inflammation involving brain, optic nerve and spinal cord. In this review, we have retrospectively analyzed the various CNS inflammatory manifestations of COVID19 reported to date. This includes acute myelitis, acute disseminated Encephalomyelitis (ADEM), acute hemorrhagic necrotizing encephalitis (AHNE), and cytotoxic lesion of the corpus callosum (CLOCC). We also discuss the relevant neuroimaging and cerebrospinal fluid markers (CSF) associated with CNS inflammation and COVID-19.

\section{Methods}

\section{Study design}

We conducted a thorough literature review in March 2021 using the terms "SARS-CoV-2 and neurological complication", "SARS-CoV-2 and CNS Demyelination" for reports of myelitis, transverse myelitis (TM), longitudinally extensive transverse myelitis (LETM), neuromyelitis optica (and spectrum disorder; NMO or NMOSD), myelitis, Acute Disseminated Encephalomyelitis (ADEM), Acute Hemorrhagic Necrotizing Encephalitis/Acute Hemorrhagic Leukoencephalitis (AHNE/AHLE), Cytotoxic lesion of the Corpus Callosum (CLOCC) and Optic neuritis (ON).

We searched PubMed, Google Scholar and Scopus databases for identifying case series and case reports published between December 01, 2019 to March 15, 2021. Review articles and consensus statements were excluded from the analysis. We used the preferred reporting items for systematic reviews and meta-analyses (PRISMA) for the display of inclusions and exclusions [12]. Based on our search criteria, 
we found articles from PubMed $(n=189)$, Google Scholar $(n=1201)$ and Scopus $(n=55)$. Amongst all, 424 cases were identified as duplicates. Finally, we screened 1021 articles for title and abstracts, and reviewed full-text literatures in accordance with our study objective after removing 918 articles which were either missing clinical information or did not meet our study objective and 70 based on exclusion criteria (Fig. 1). The review was limited to articles in English.

We included 33 publications and 43 cases for review for observational analysis that met our below-mentioned inclusion criteria, out of which 15 were of acute myelitis including transverse myelitis, 10 cases of ADEM, 6 cases of CLOCC, 9 cases of AHNE/AHLE. Apart from these one case of myelitis, considered by the authors to be Clinically isolated syndrome (CIS), and two cases had MOG mediated demyelinating disease. One MOGAD patient presented with optic neuritis and one with optic neuritis and myelitis. We excluded statistical analysis of MOGAD disorders as a separate entity as well as one CIS case due to low sample size although we describe these cases in "Discussion". Therefore 40 cases of COVID-19 and CNS inflammatory disorder were reviewed for descriptive quantitative analysis.

\section{Inclusion criteria}

The inclusion criteria for the published studies included: (1) Patient age $\geq 18$ years; (2) COVID-19 diagnosis confirmed by RT-PCR nasopharyngeal or serum antibody test; (3) CSF study findings in COVID-19 and MRI imaging performed; (4) CNS specific disorders including ADEM, AHNE/AHLE,

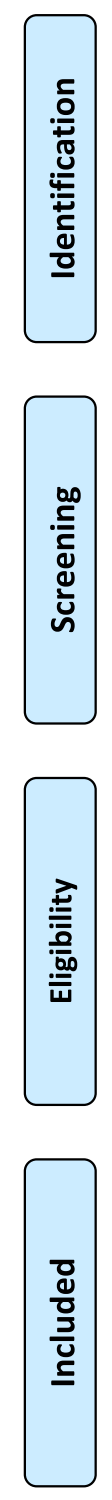

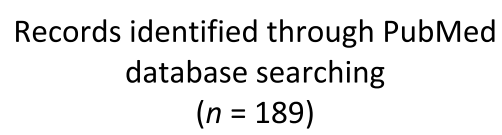
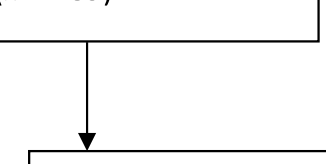

Records after duplicates removed $(n=1021)$
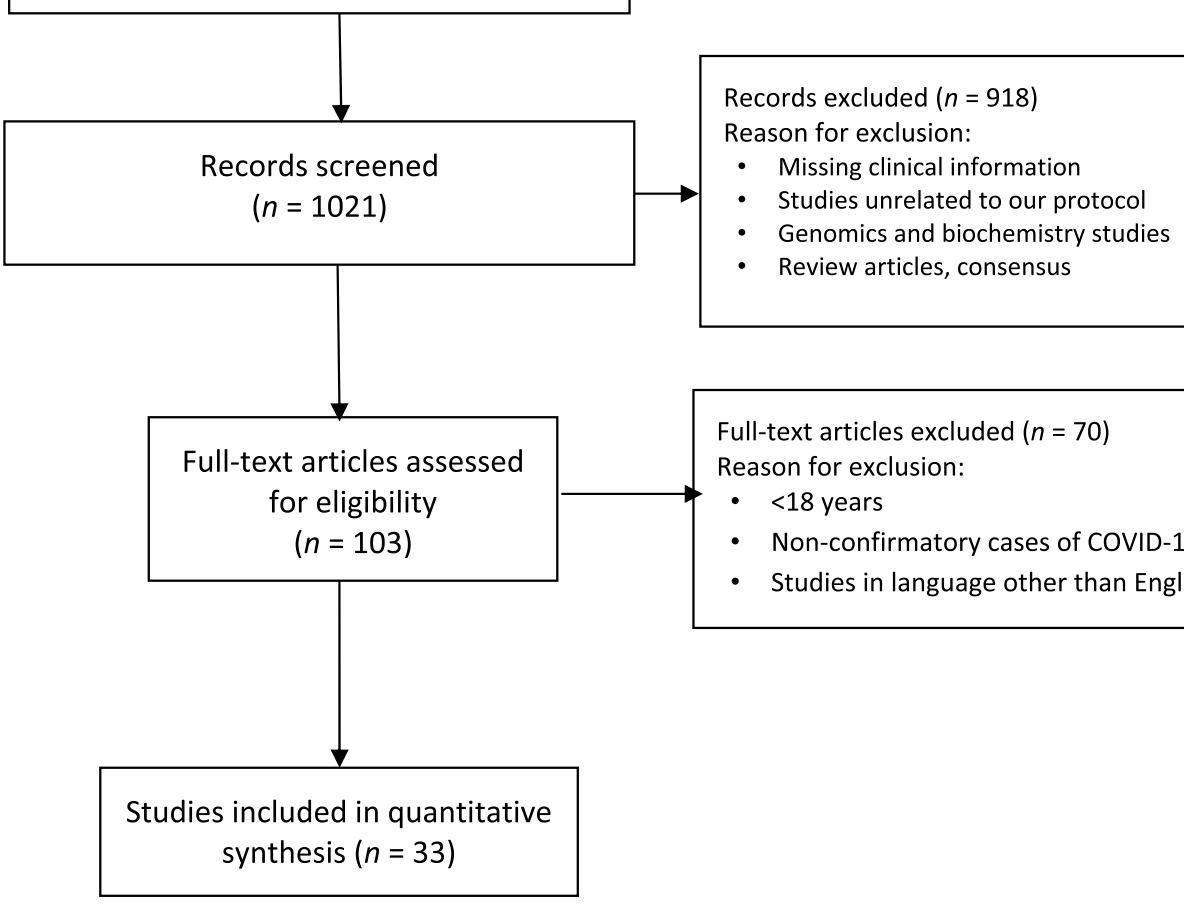

Additional records identified through others (Scopus, Google Scholar) database searching $(n=1076)$

- Studies unrelated to our protocol

- Review articles, consensus

Fig. 1 Preferred Reporting Items for Systemic Reviews and Meta-Analysis (PRISMA) Flow Diagram 
CLOCC, acute myelitis including transverse myelitis and longitudinally extensive myelitis and $\mathrm{ON}$.

\section{Exclusion criteria}

The exclusion criteria from the published studies include: (1) Patient age $<18$ years; (2) Duplicate articles which involved repetition of cases (3) Articles in languages other than English; (4) Studies that had no available individual patient's data; (5) Editorials; (6) Articles and reported literature on CNS and peripheral nervous system (PNS) disorders other than acute myelitis, ADEM, AHNE/AHLE, CLOCC and ON.

\section{Quality assessment}

The critical appraisal checklist for case reports provided by the Joanna Briggs Institute (JBI) was used to perform assessment of overall quality of case series and case reports [13].

\section{Data acquisition}

Two reviewers independently performed the literature search. From the selected articles, we extracted the following data for our analysis: study type, date of publication, age, gender, clinical presentation of COVID-19, diagnostic tests for SARS-CoV-2 infection including RT-PCR nasopharyngeal, CSF SARS-CoV-2 RT-PCR and serum antibodies, CSF markers including cell count, protein, severity of COVID19 (based on IDSA/ATS criteria), treatment, neuroimaging including MRI findings. Severity of COVID-19 was measured using IDSA/ATS criteria [14].

\section{Data analysis}

We performed demographic analysis including age, gender, severity of COVID-19 cases and outcome of the cases where provided. Pooled descriptive analyses were conducted to assess differences in these markers among groups including severe vs non-severe, fatal vs non-fatal outcomes.

\section{Results}

Based on our literature search, we found a total of 40 cases with COVID-19 diagnosed with various CNS inflammatory disorders for the descriptive quantitative analysis. These included 35 case reports and 2 case series published from 16 different countries. Of the 40 cases, 14 were from the USA, 4 cases from France, 3 cases from UK, 2 each from the Italy, Qatar, India, Belgium, Iran and one each from UAE, Australia, Brazil, Germany, Spain, Moldova, Japan, Singapore and Switzerland. Summarized information of these cases is presented in Tables 1, 2, 3 and 4.

The demographic characteristics including severity of COVID-19, outcomes, treatment, MRI abnormality is summarized in Table 5. The main cohorts of CNS inflammatory disorder include acute myelitis including transverse myelitis (TM) /LETM and optic neuritis, ADEM including AHLE/ANHE and CLOCC. Out of the entire cohort, there were 14 patients $(35 \%)$ with age $<50$ years, and the remaining 26 patients $(65 \%)$ were aged $>50$ years. The mean age was $50.7(\mathrm{SD} \pm 15.1)$ years, median age was 52.5 years, with age ranging from 21 to 75 years. Amongst the total of 40 patients in the the statistical analysis, 27 patients were male $(68 \%)$ and the other 13 were female (32\%). Of the 40 cases, $37 \%(n=15)$ had transverse myelitis, 25\% $(n=10)$ ADEM, $15 \%(n=6)$ AHNE/AHLE, and $23 \%(n=9)$ CLOCC/MERS. Based on IDSA/ATS criteria of either requiring vasopressor for septic shock or mechanical ventilation, $49 \%(n=18)$ of patients were considered to have had a severe COVID infection. In our review, 19\% $(n=7)$ were fatal (Table 5).

In terms of medications received, $71 \%$ of the patients $(n=25)$ were given intravenous methylprednisolone (IV MP), 26\% ( $n=9)$ were given intravenous immunoglobulin G (IVIG), while $23 \%$ of the patients $(n=8)$ received plasma exchange/plasmapheresis (PLEX) for management of various neurological inflammatory disorders. For management for COVID-19, $6 \%$ of the patients $(n=2)$ were given azithromycin, $9 \%(n=3)$ were given hydroxychloroquine (HCQ), while $14 \%(n=5)$ received a combination of HCQ and azithromycin. No patient received tocilizumab. Abnormal contrast enhancement in MRI imaging of the spine and brain was reported in 10\% $(n=4)$ and $23 \%$ $(n=9)$ respectively (Table 5).

The comparisons of severity, outcomes, and CNS manifestations (acute myelitis, ADEM, AHNE/AHLE, and CLOCC/MERS) against age, gender, CSF protein, and elevated cell count are shown in Table 6. However, a statistically significant difference was observed in the CSF cell count amongst patients with a non-severe compared to patients with severe COVID-19 infection.Seventy nine percent (11/14) of the reported elevated cell counts were in patients with a non-severe as compared to patients with severe COVID-19 infection where only $21 \%$ of cases had elevated cell counts $(3 / 14)(p=0.03)$, whereas $71 \%$ of those with transverse myelitis have elevated cell count. Elevation of the CSF protein levels among the various pathologies also showed a difference that was borderline significant. No significant differences were seen in other variables with regards to age, gender, and CSF characteristics (Table 6). 


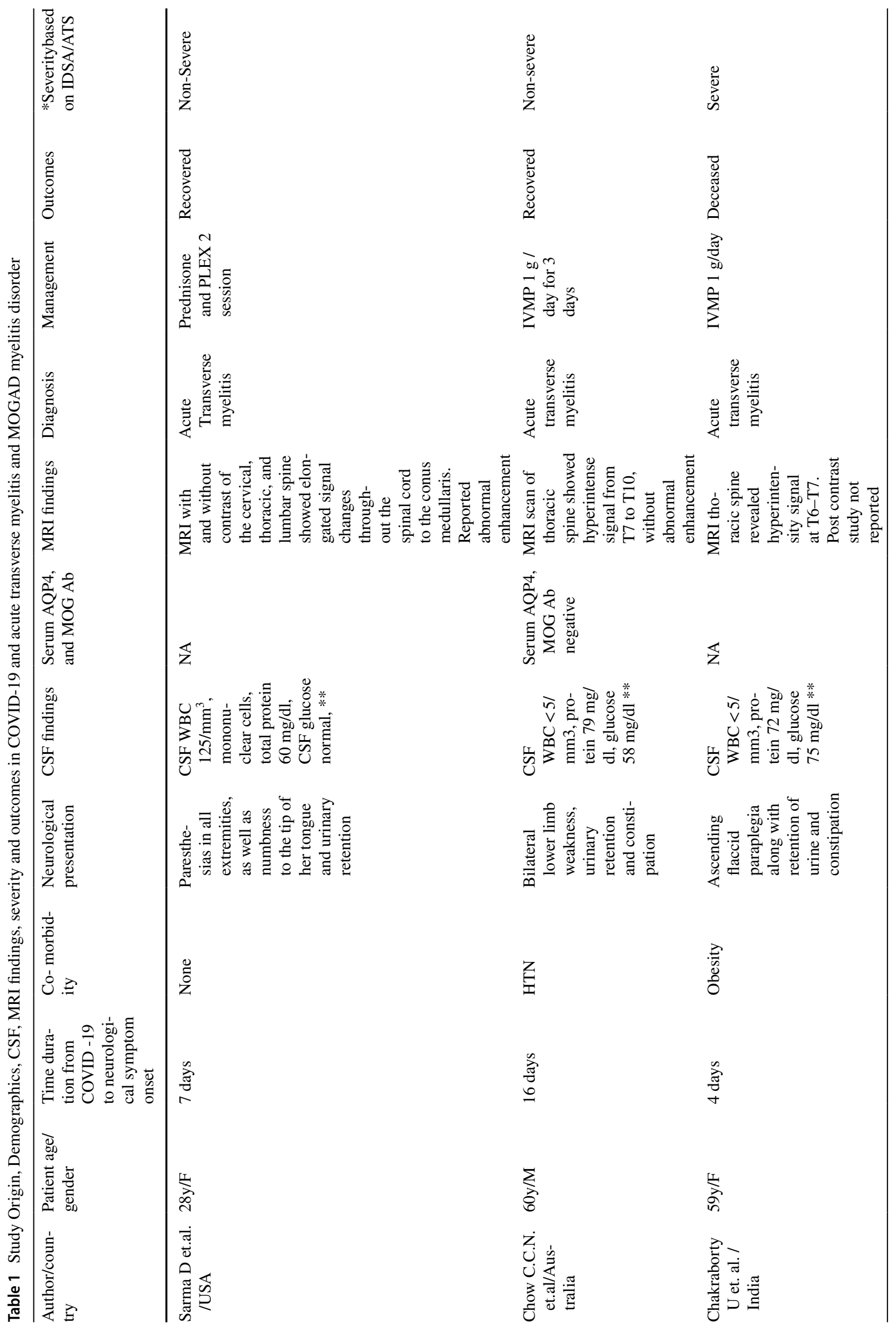




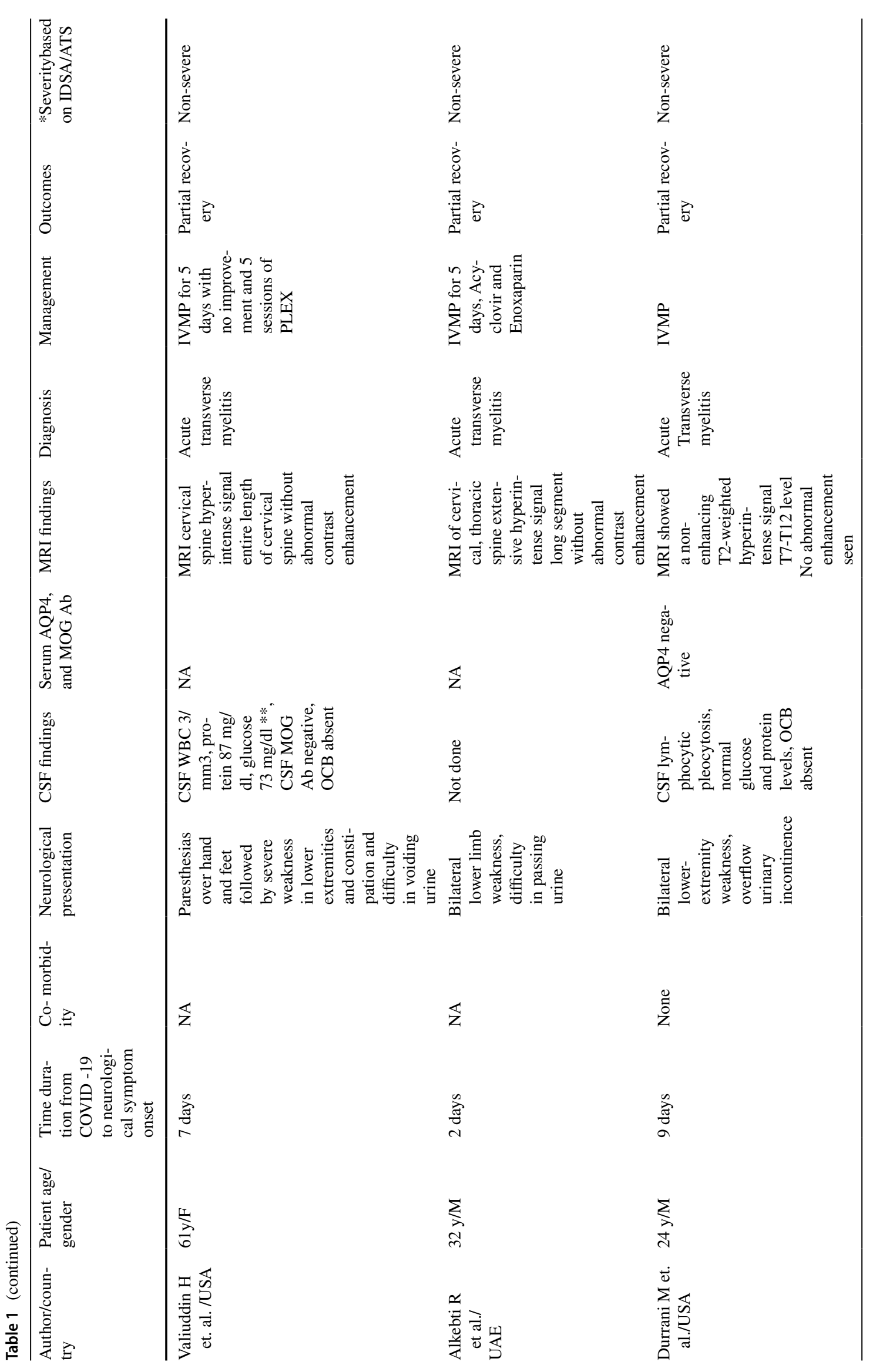




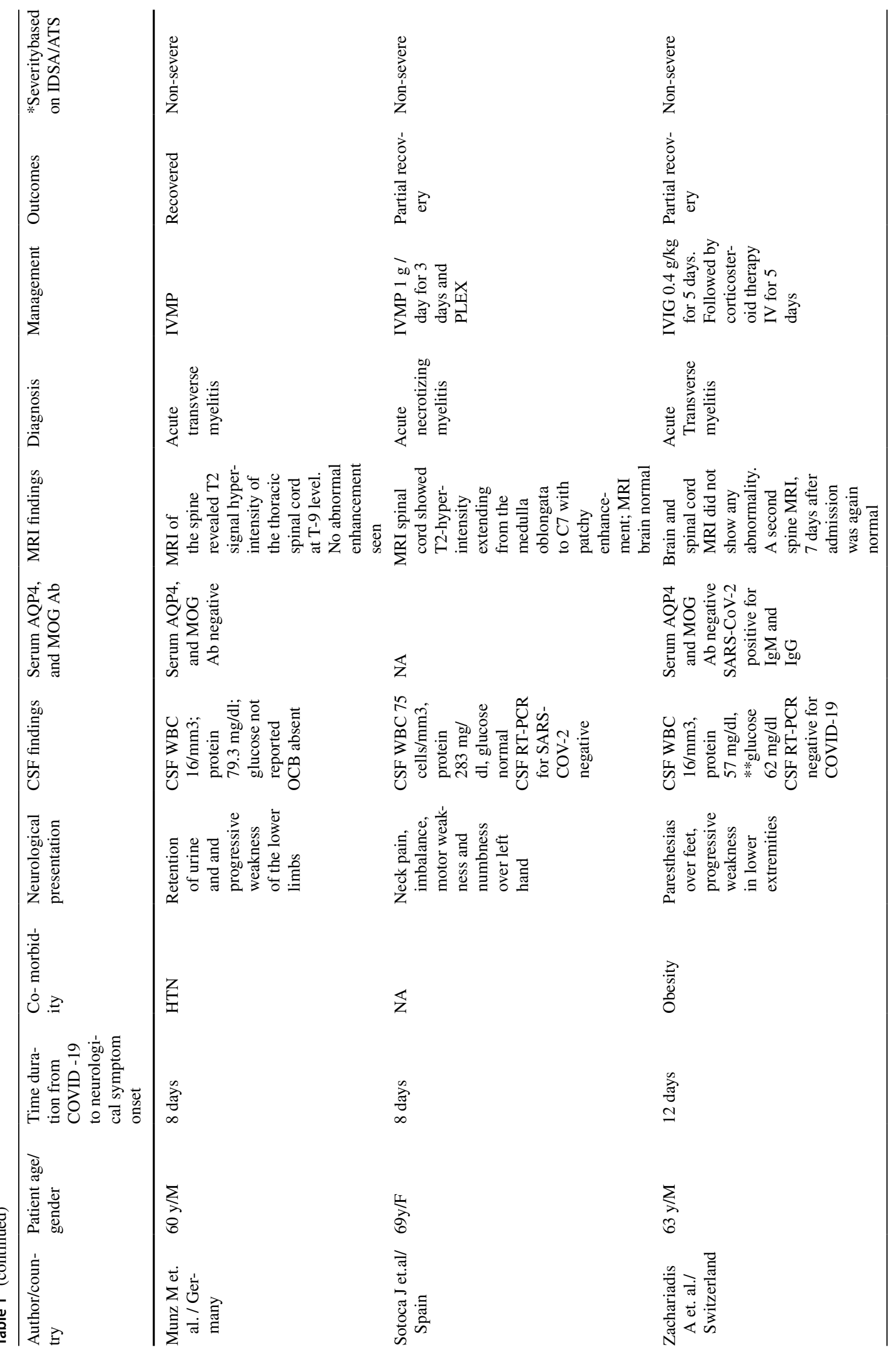




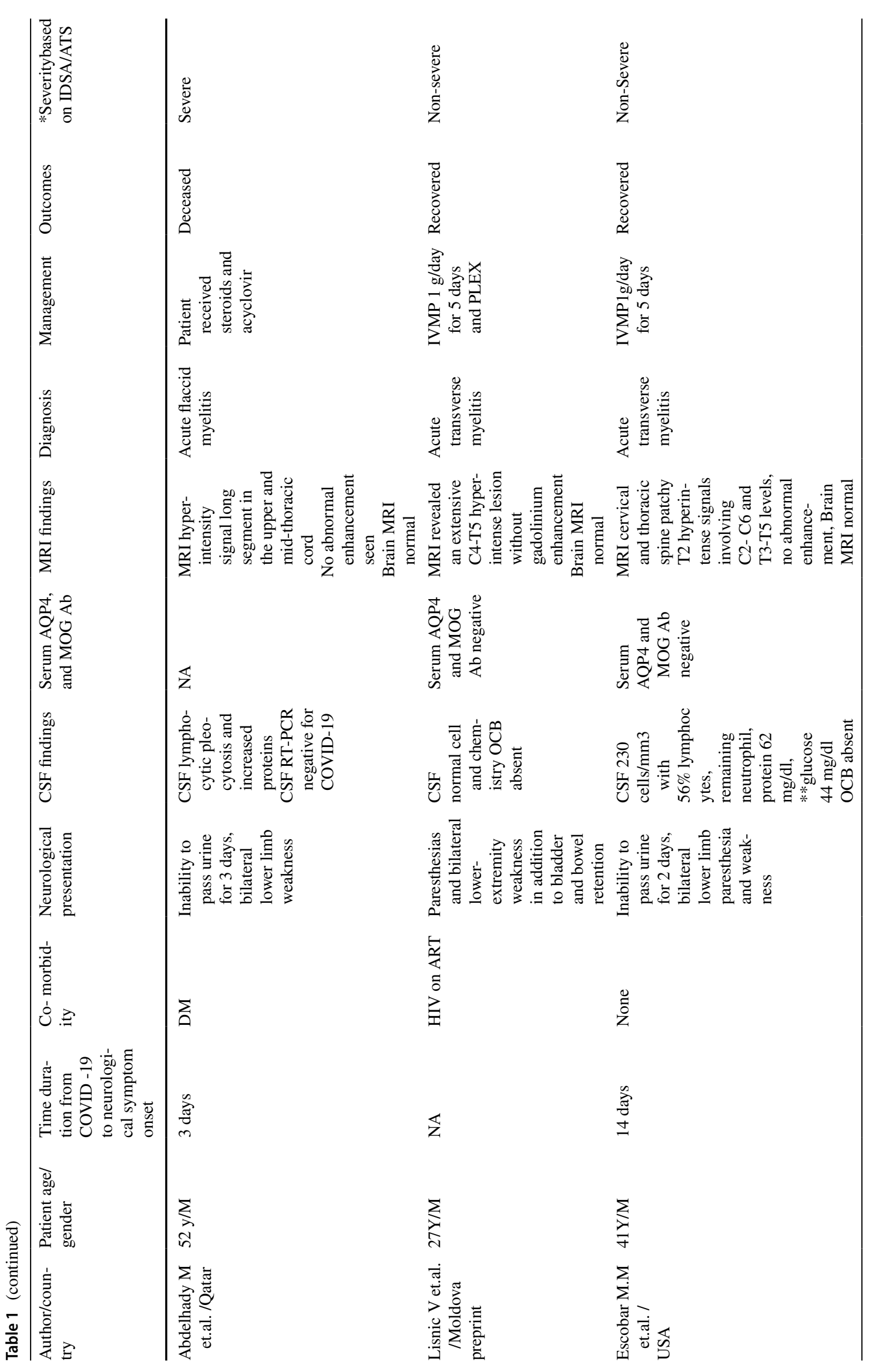




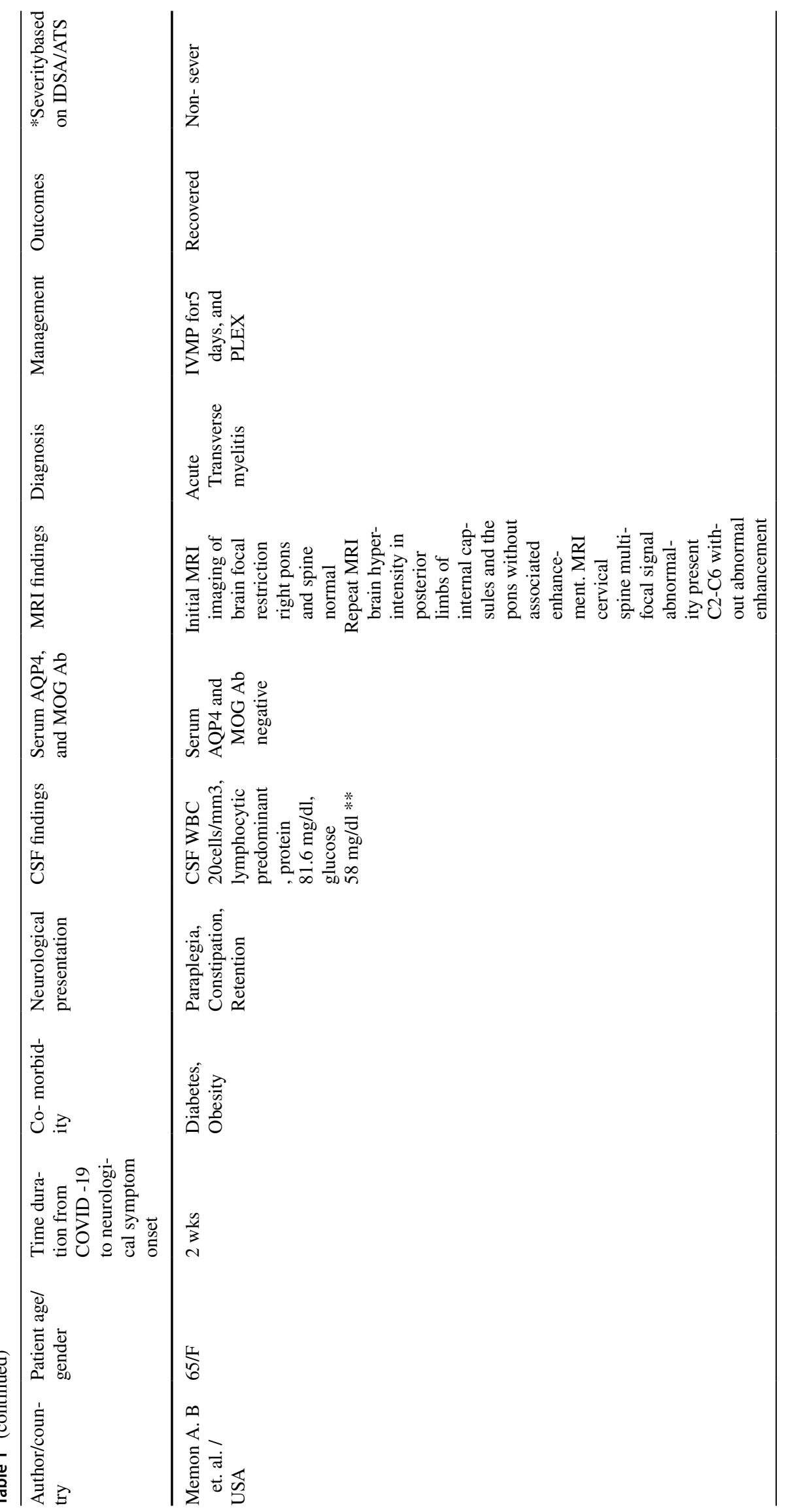




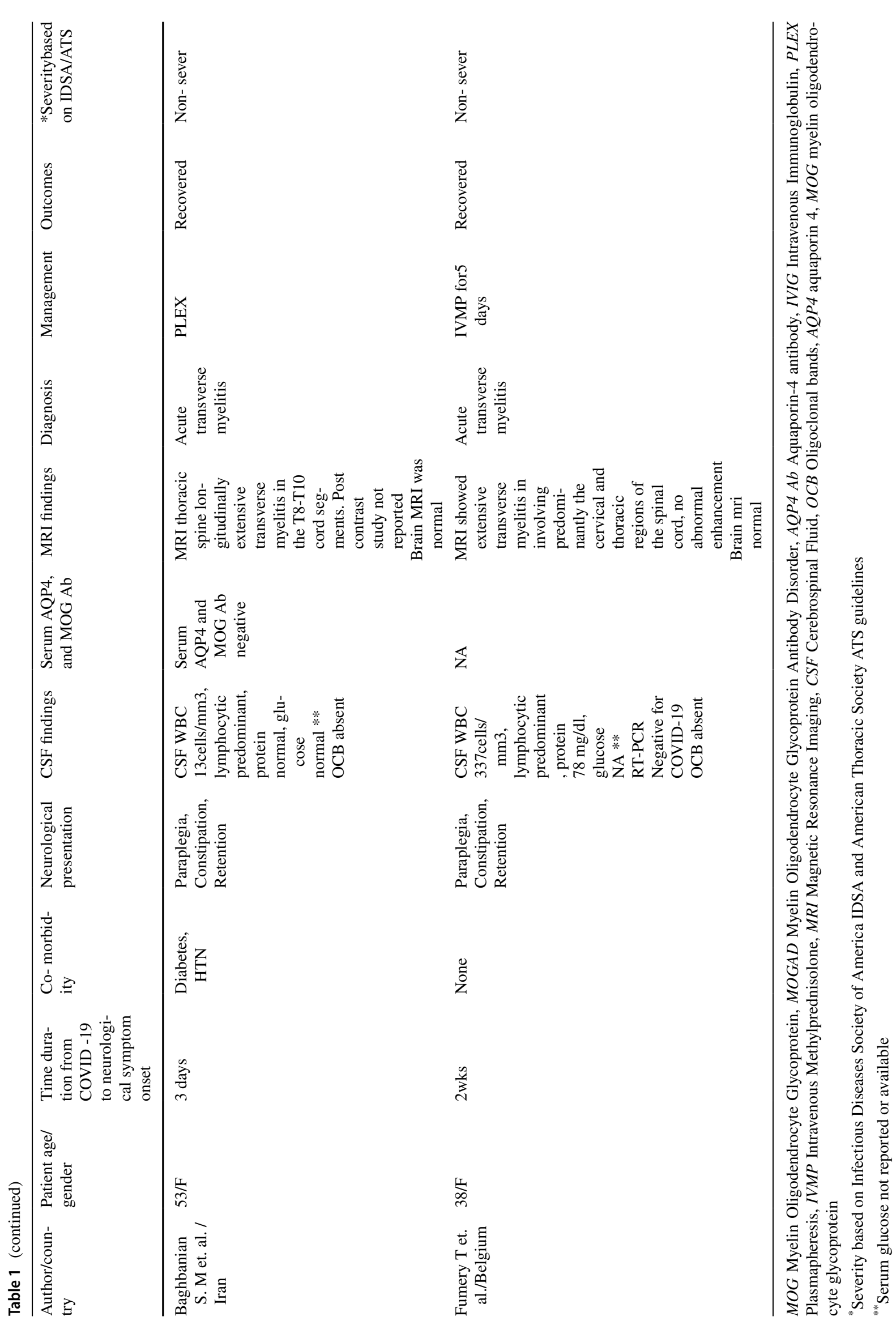




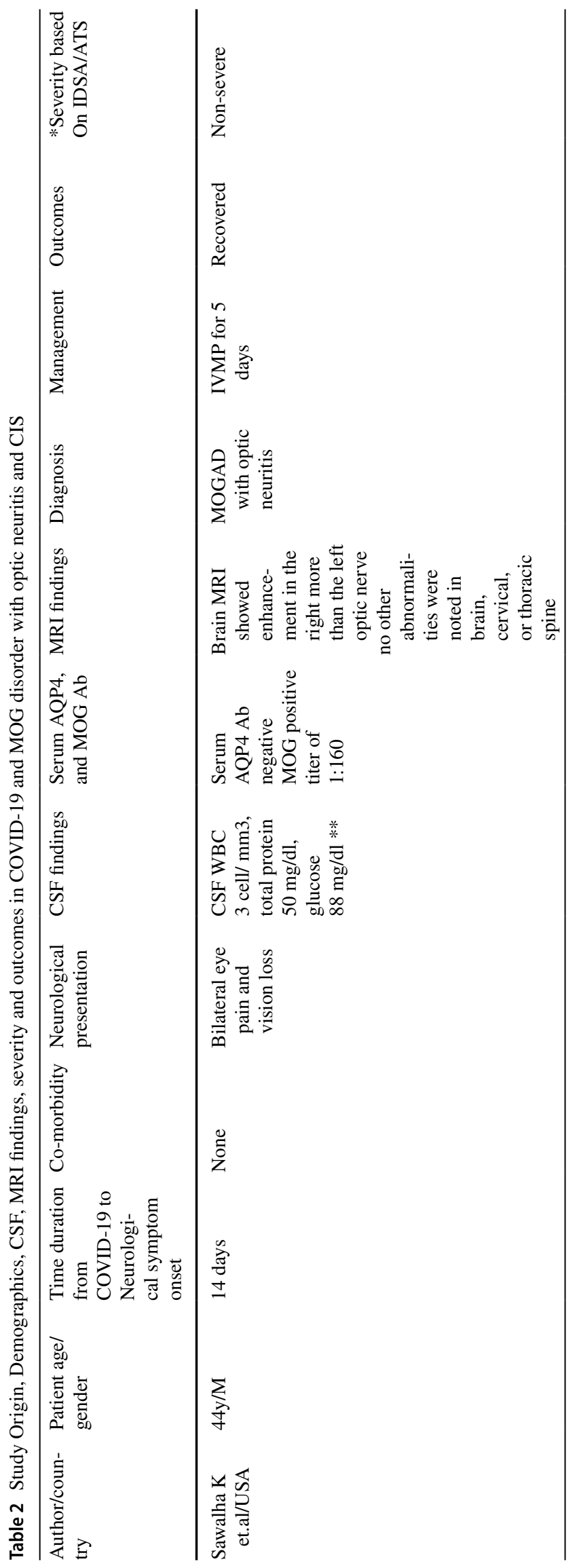




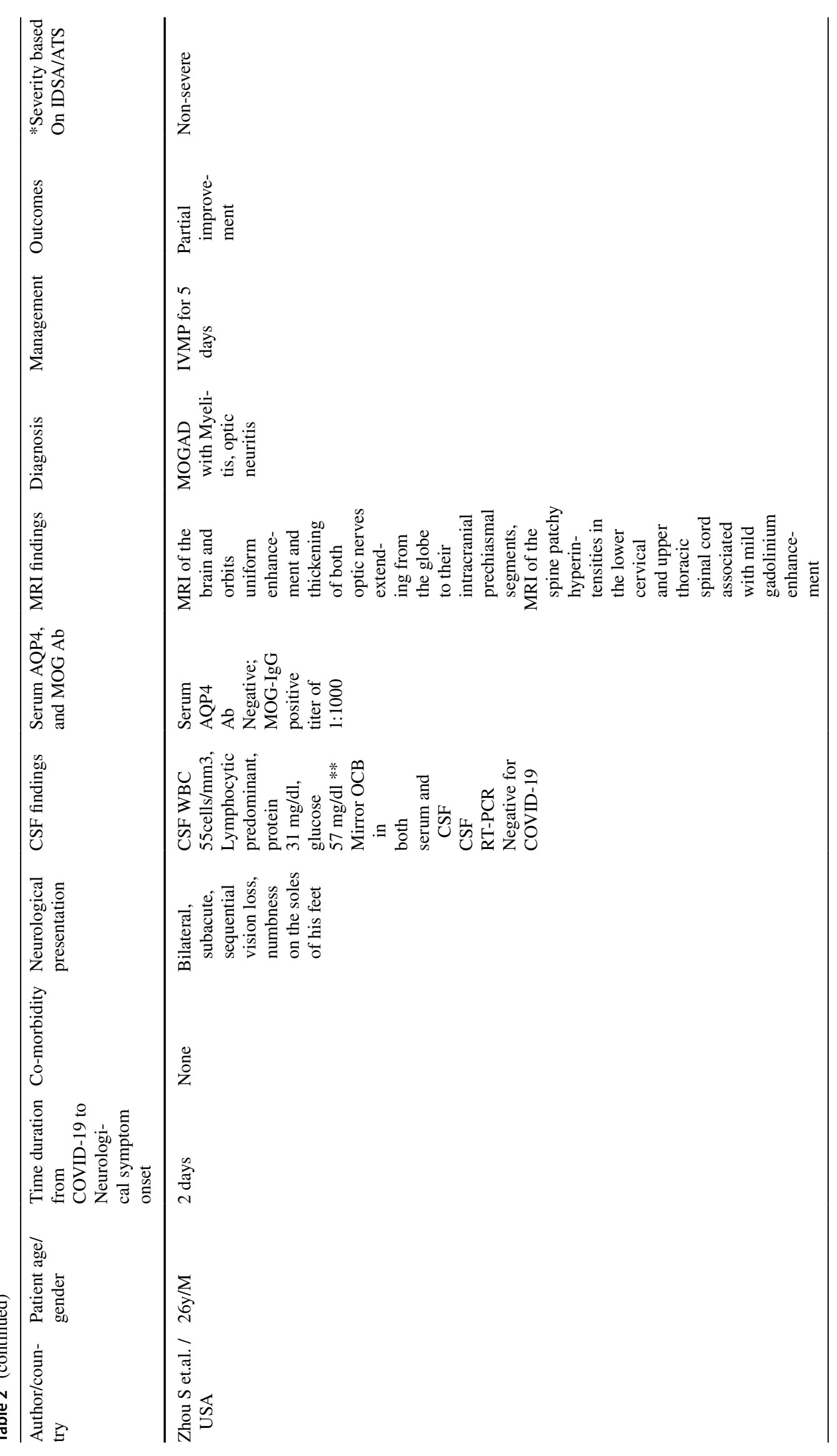




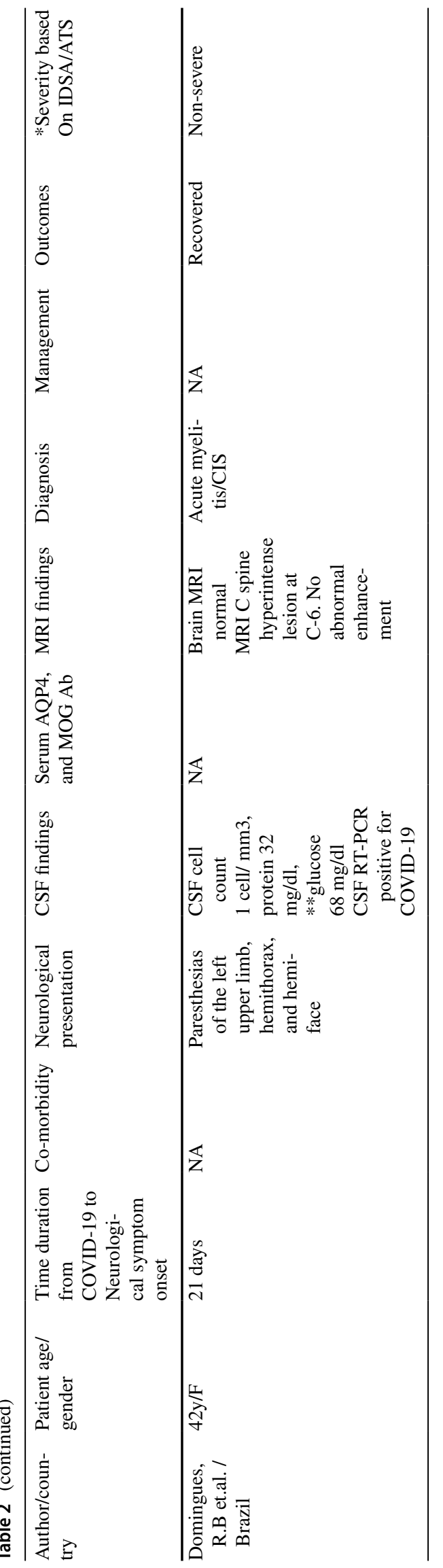

\section{Discussion}

It is now well known that infection with SARS-CoV-2 causes a multi-systemic inflammatory/immunological response. Although the exact mechanism responsible for postinfectious neurological disorders is not fully understood, the diverse neurological presentations of COVID-19 have been attributed to the underlying immunological mechanisms $[10,15$, 16]. It is hypothesized that in some instances the $\mathrm{T}$ cell and/ or antibody immune reaction against the infectious agent is directed against a CNS cell or structure because of similarities between some component of the infectious agent and a protein, lipid or carbohydrate component of the CNS. This which once was called cross-reactivity is now known as molecular mimicry. Even though a strong immune response is essential for protective adaptive immunity, a prolonged and overactive immune response contributes to pathological tissue injury [17]. This immune response has garnered attention towards a phenomenon called "cytokine storm" which is associated with high fever, respiratory distress, multi-organ failure and increased mortality over the first 2 weeks in COVID-19 patients [18, 19].Currently, little is known about the lasting neurological effects of the "cytokine storm". In this systematic review of 43 patients, 40 subjected to staitical analysis with a spectrum of CNS inflammatory disorders in COVID-19 patients, the most common presentation was that of acute myelitis, often transverse, followed by ADEM, CLOCC/MERS, and AHNE/AHLE. The timing of neuroinflammatory complications relative to initial symptoms of COVID-19 infection and the rarity of detection of SARS-CoV-2 in CSF or CNS, suggest that most of these particular CNS syndromes reviewed in this paper are parainfectious/postinfectious disorders [9, 20-22]. The patients in this review exhibited a wide variety of neurological symptoms of which the most common presentation in myelitis was urinary retention and lower limb weakness [22-37]. ADEM mostly presented with decrease level of mentation [21, 38-43], CLOCC/MERS with altered sensorium [44-51] and AHNE/AHLE with reduced consciousness and coma [52-57].

In terms of diagnostic test for COVID-19 in our review all CNS inflammatory disorders were diagnosed with positive nasopharyngeal RT-PCR, whereas CSF RT-PCR SARSCoV-2 was positive in two cases of ADEM [21, 41]. Serum SARS-CoV-2 IgG and IgM antibodies were positive in a case of TM [32]. It is unknown if the CNS disease is due to the direct invasion. CSF protein was found to be elevated in 11 cases of transverse myelitis including a case of myelitis, 5 cases of ADEM and 4 cases of AHNE/AHLE suggestive of underlying neuroinflammatory process and changes in blood brain or blood meningeal barriers. Similar to our reports, another study also showed increased CSF protein level in 


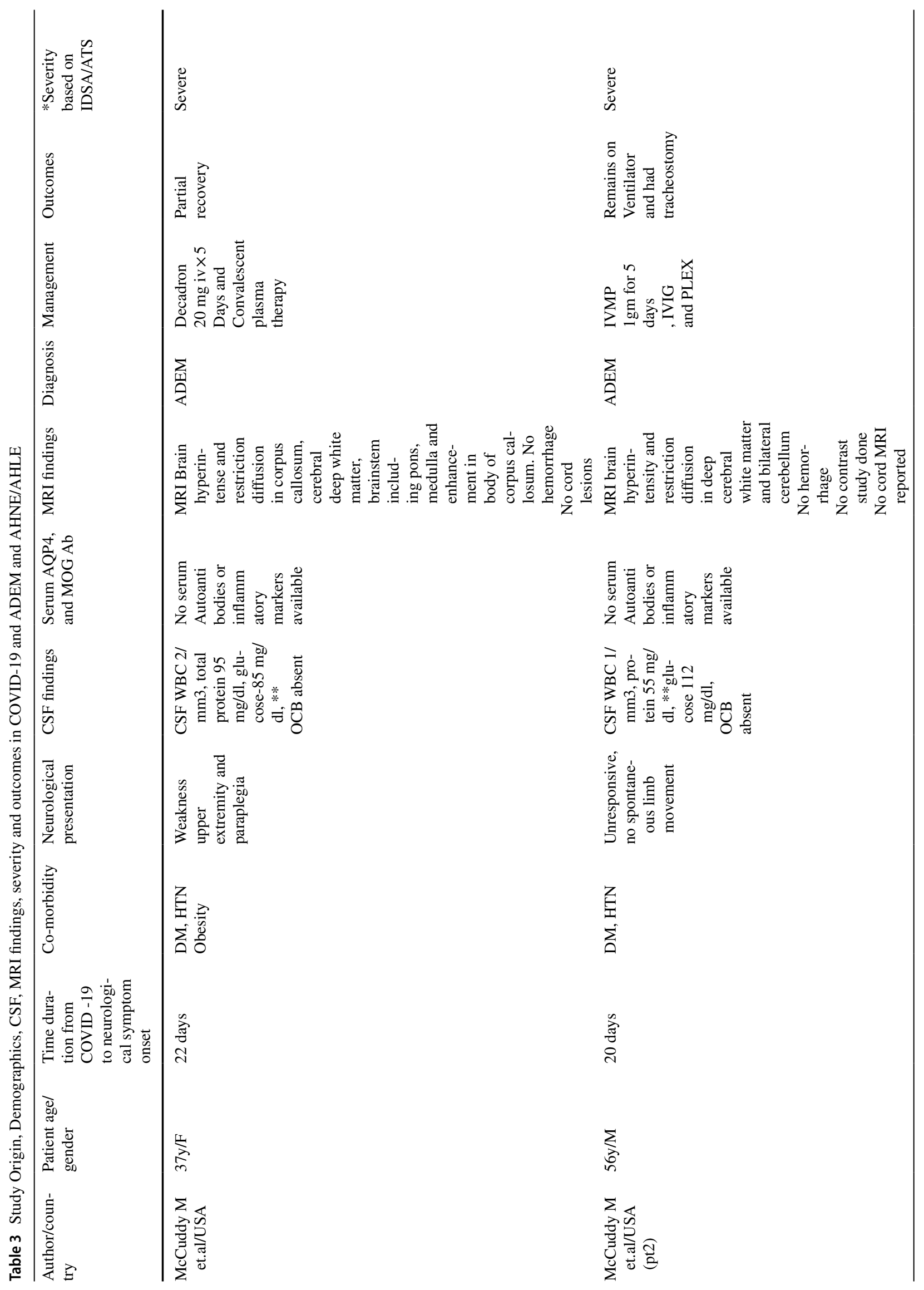




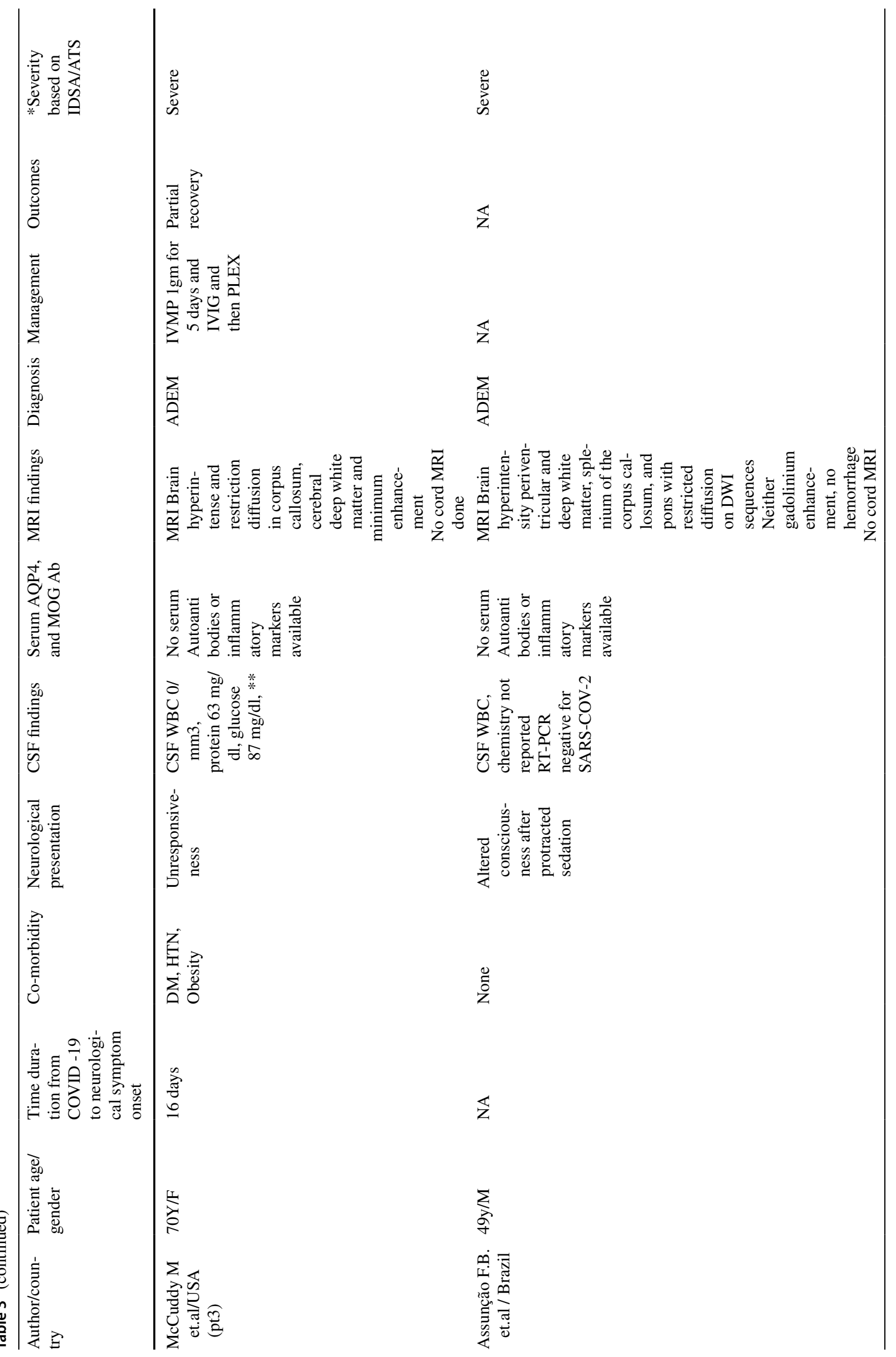




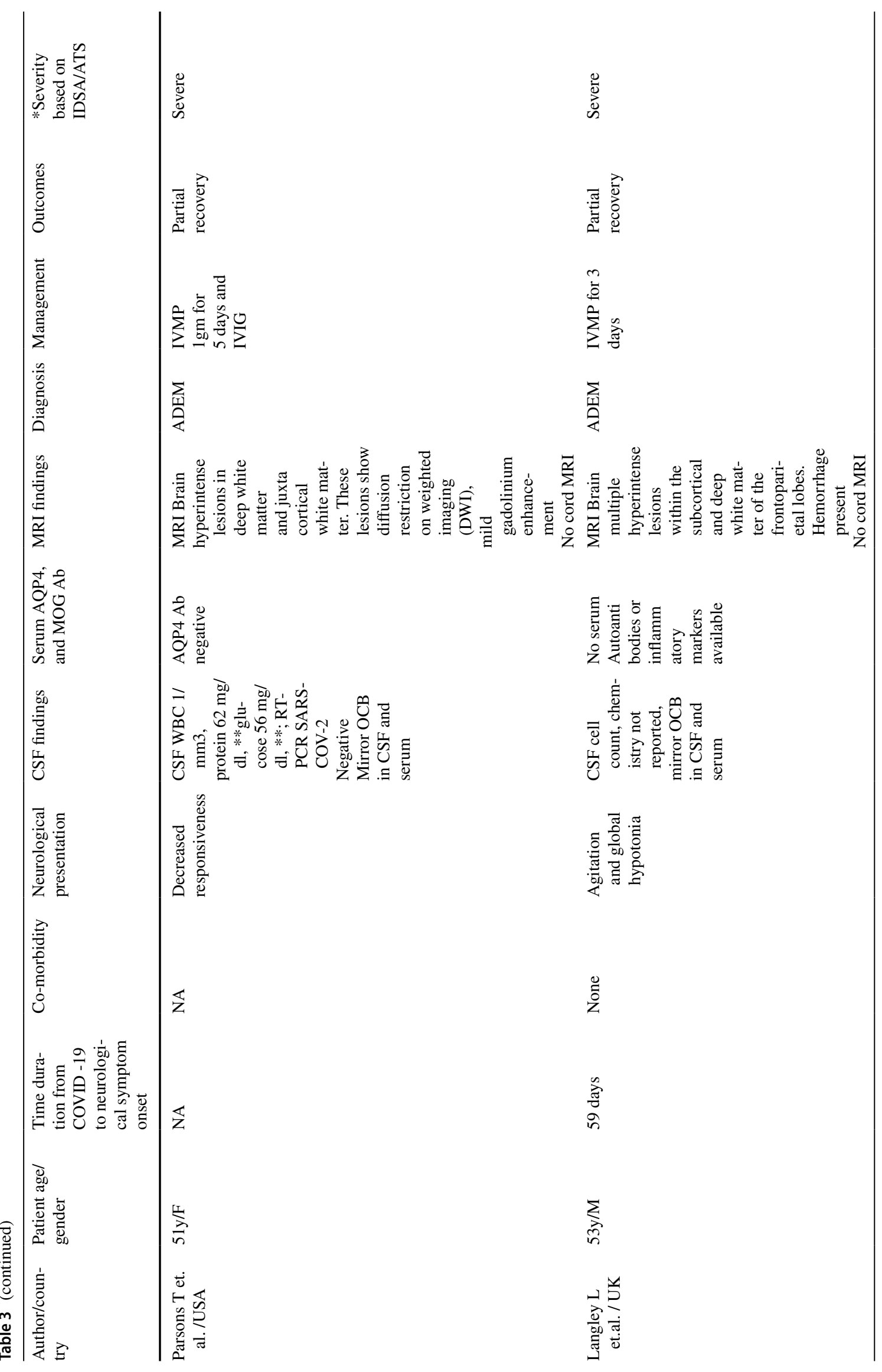




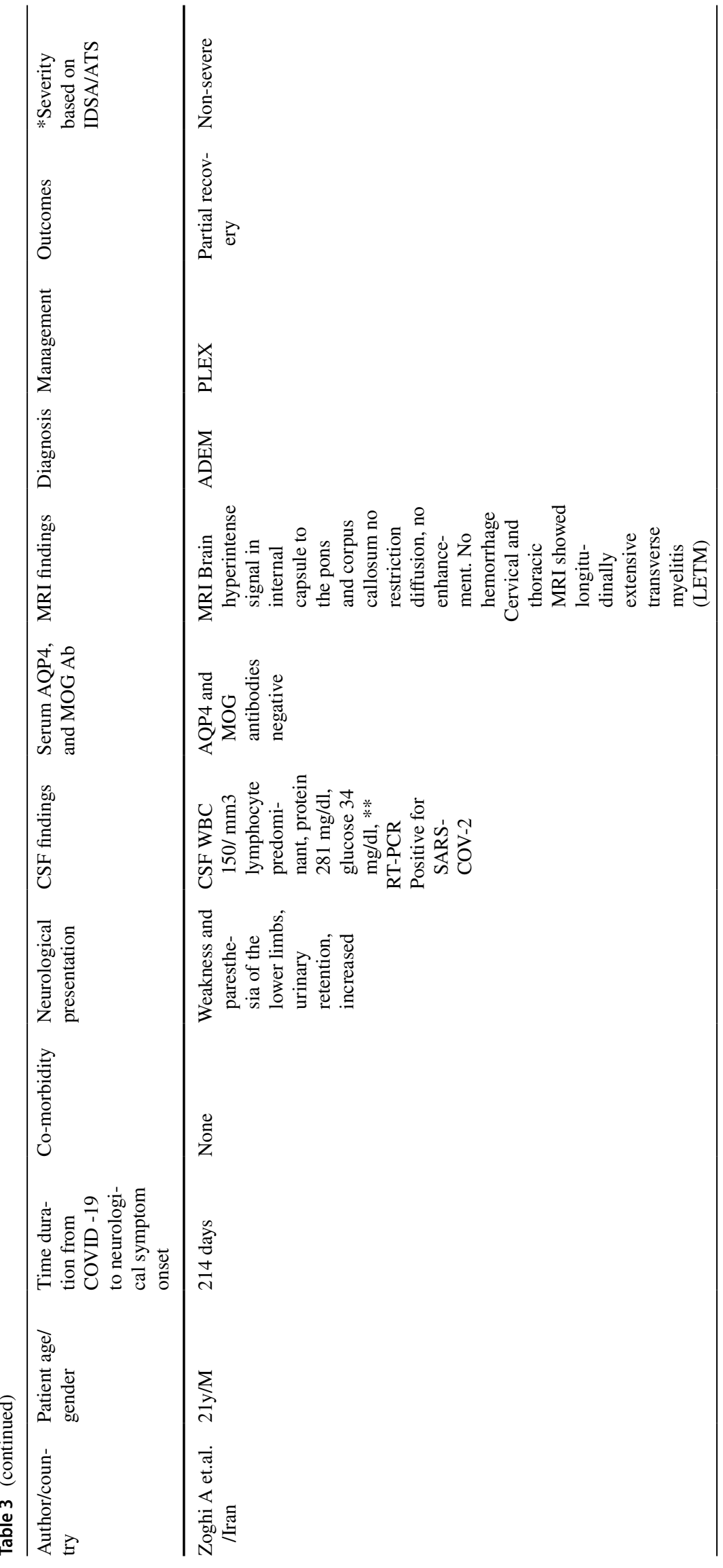




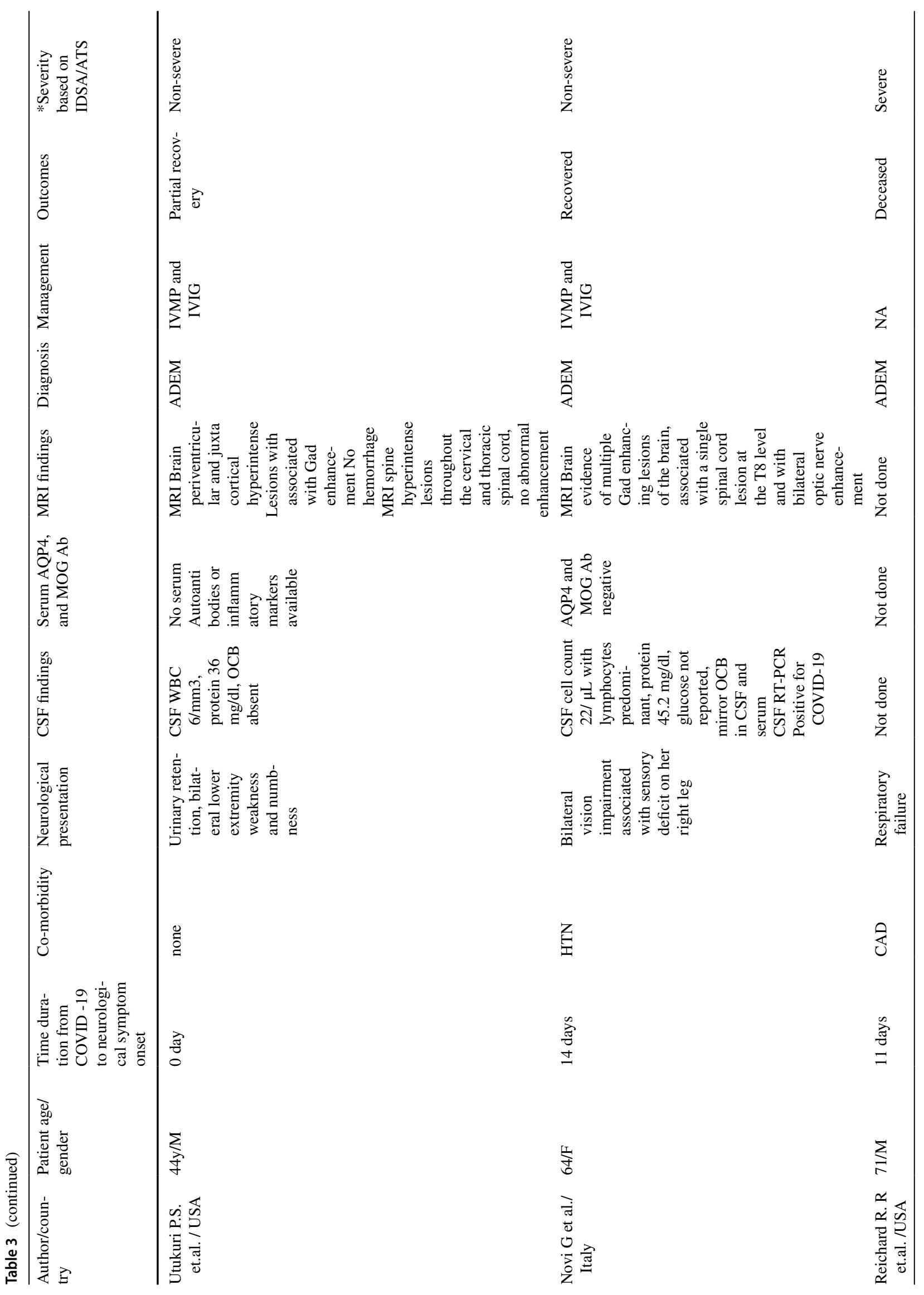




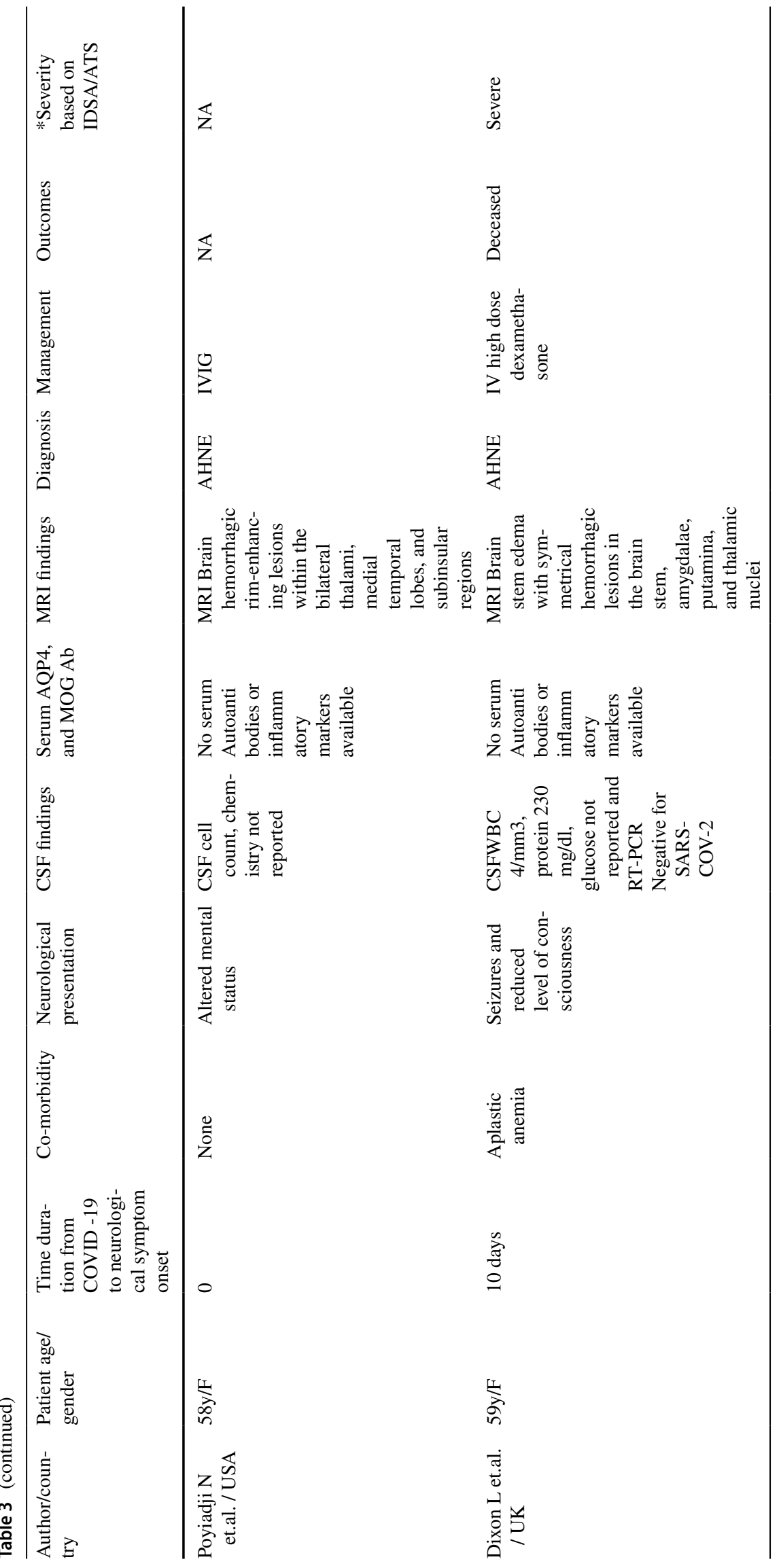




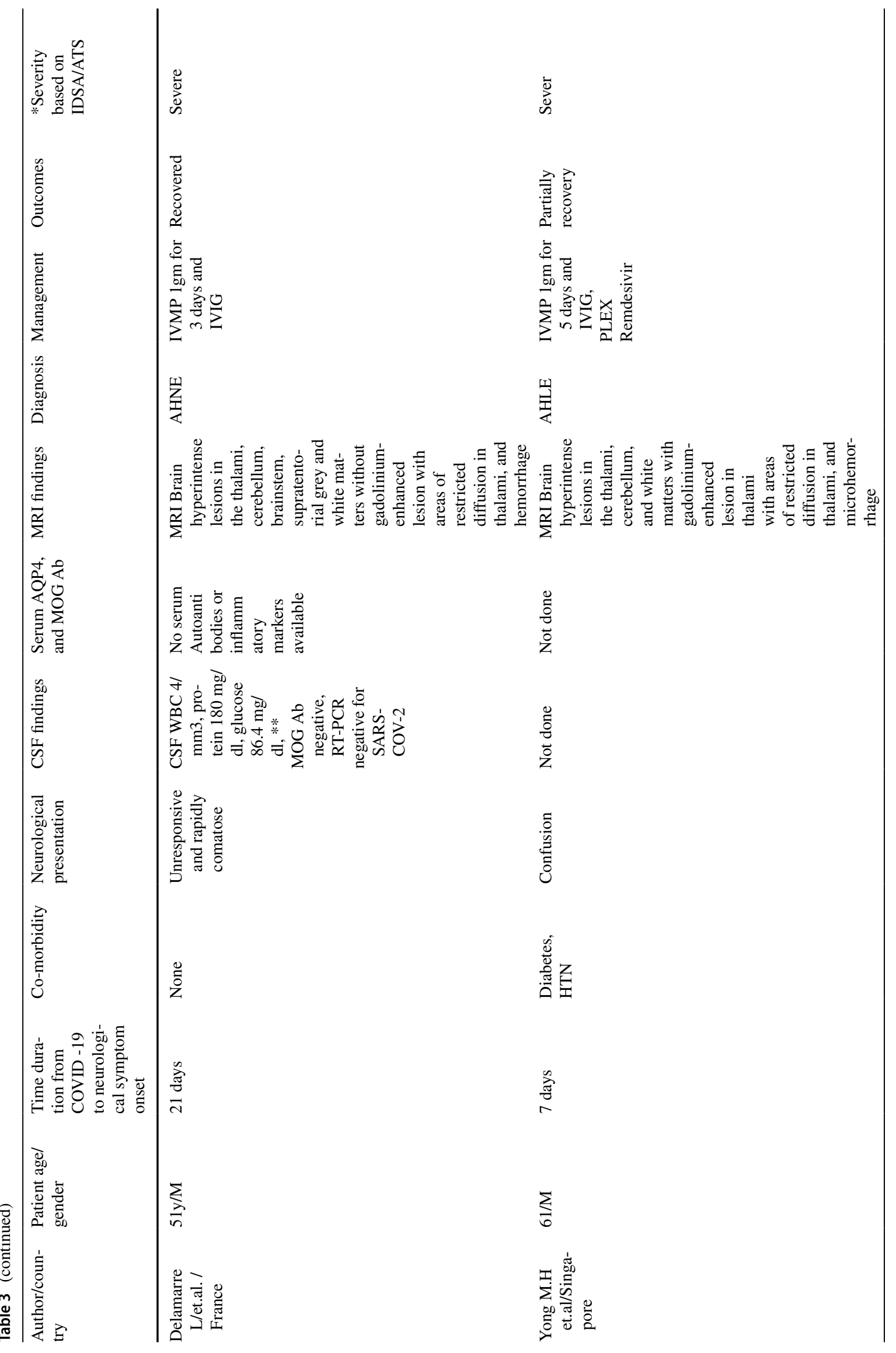




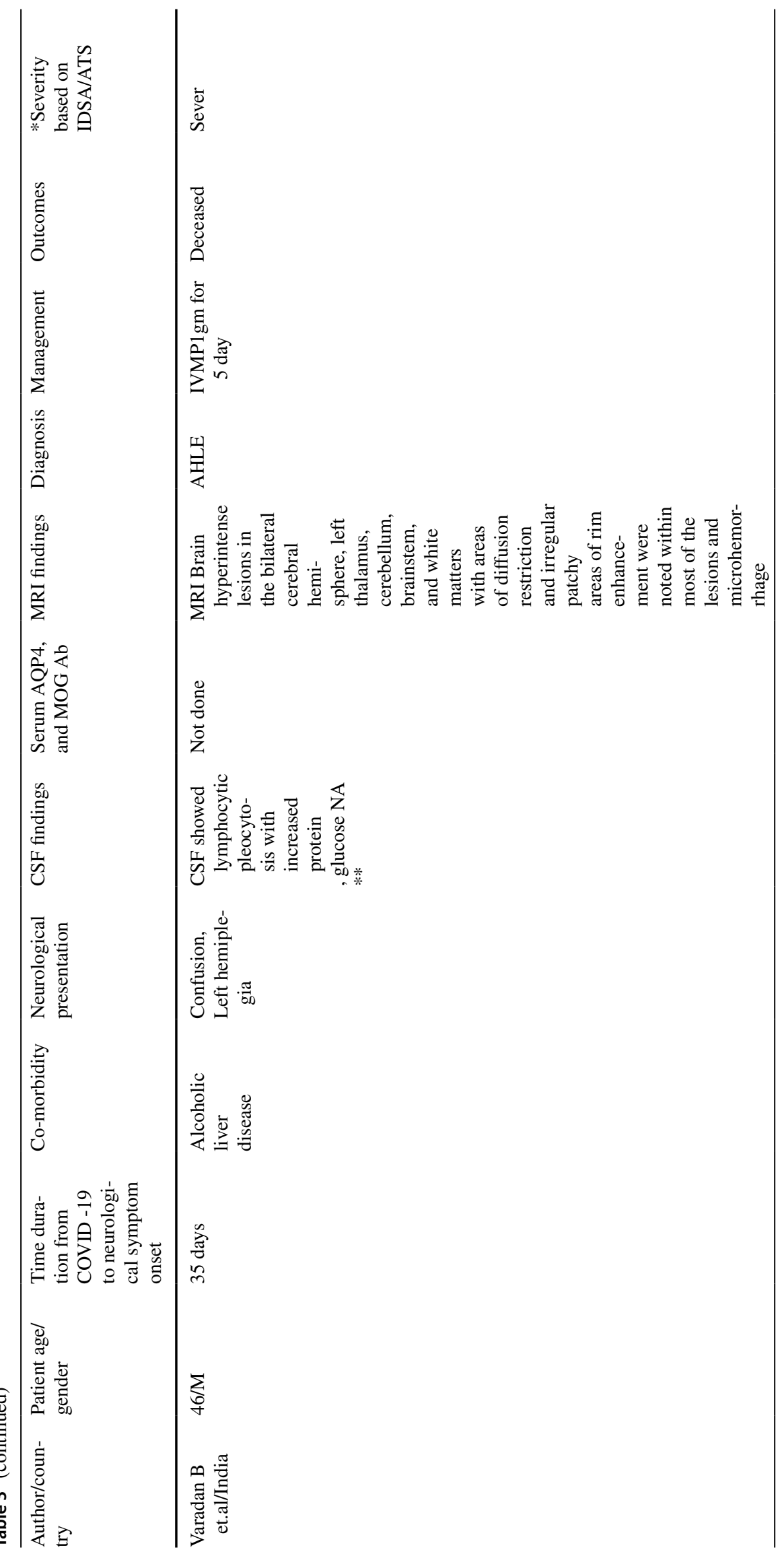




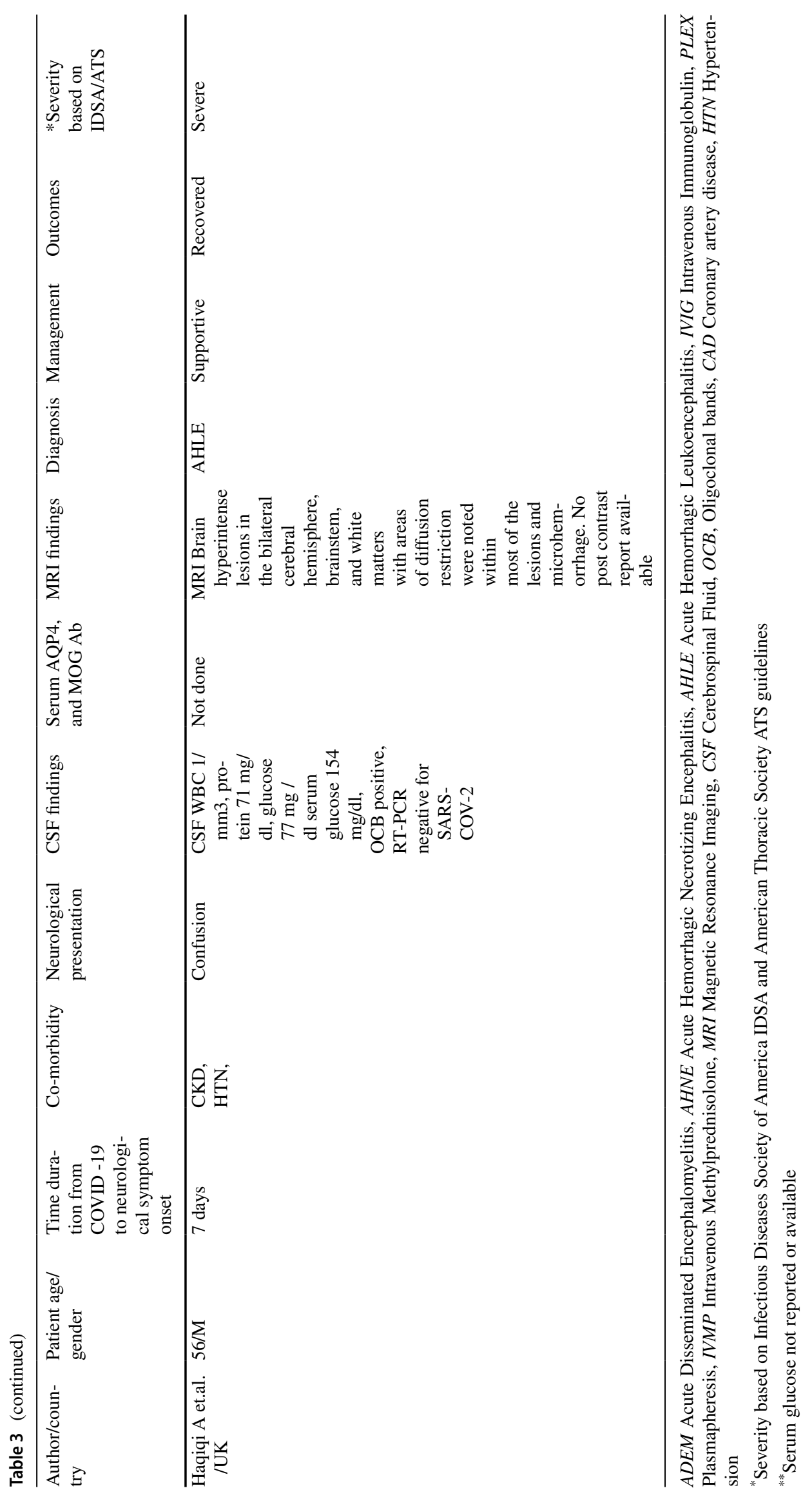




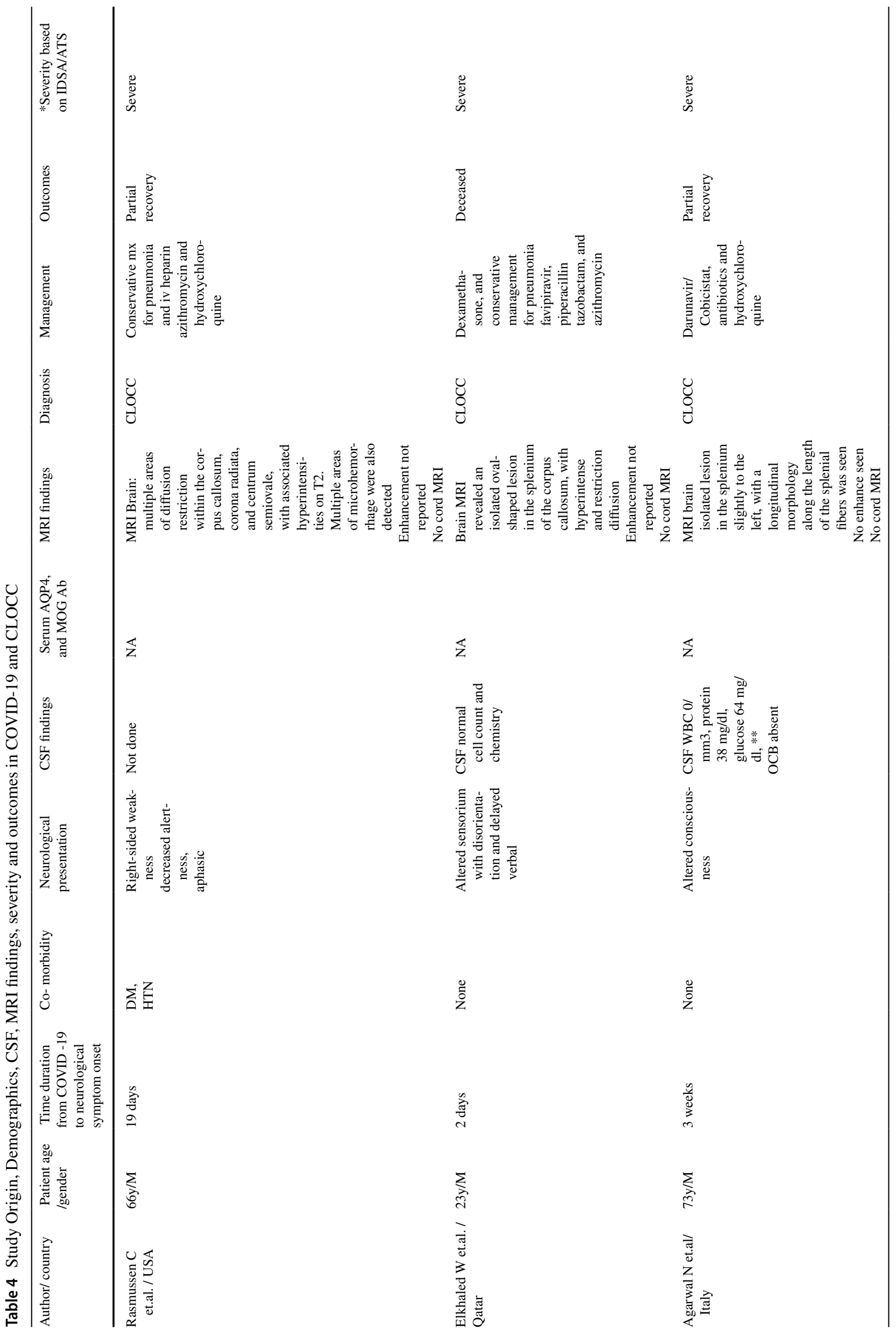




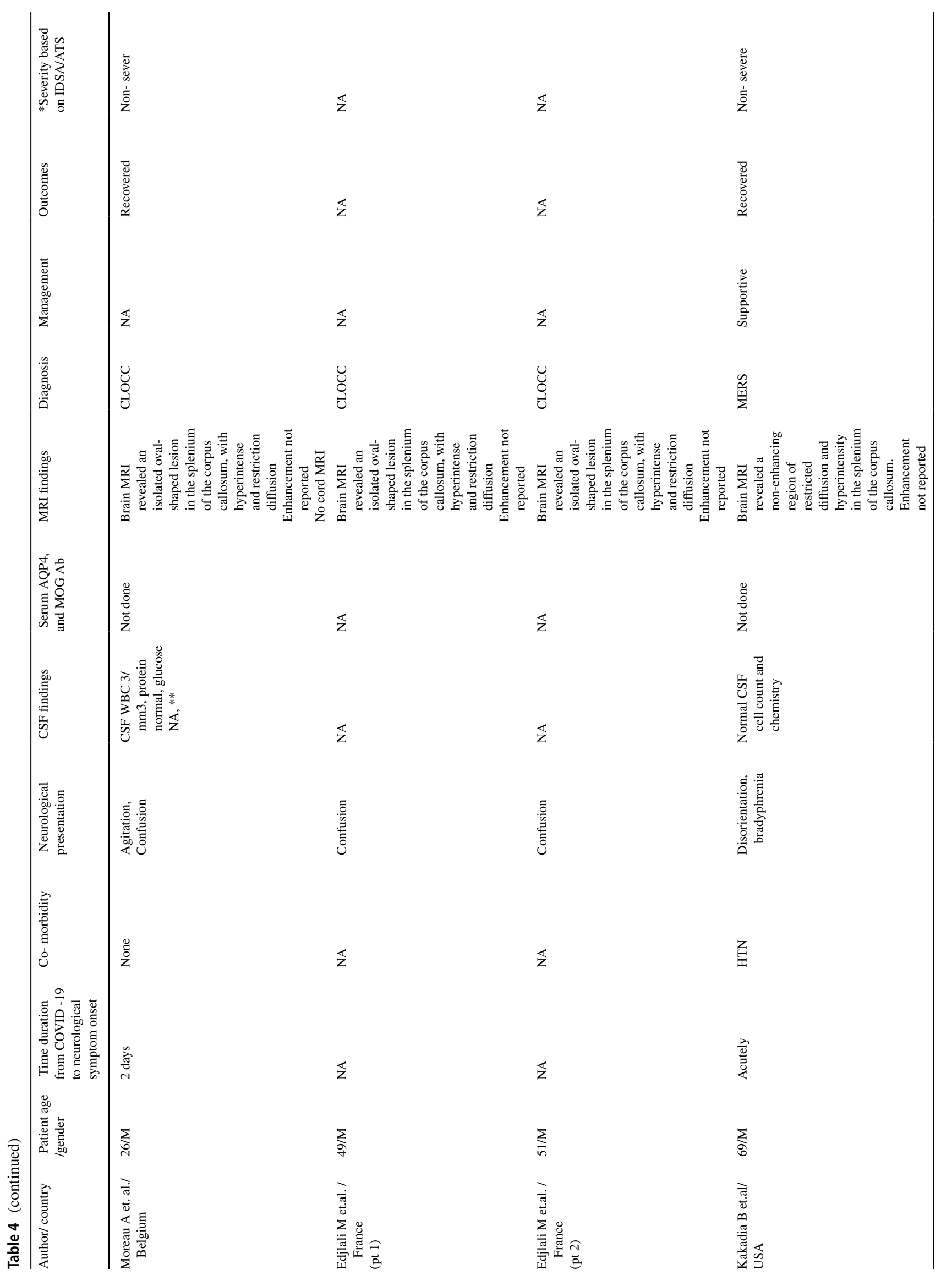




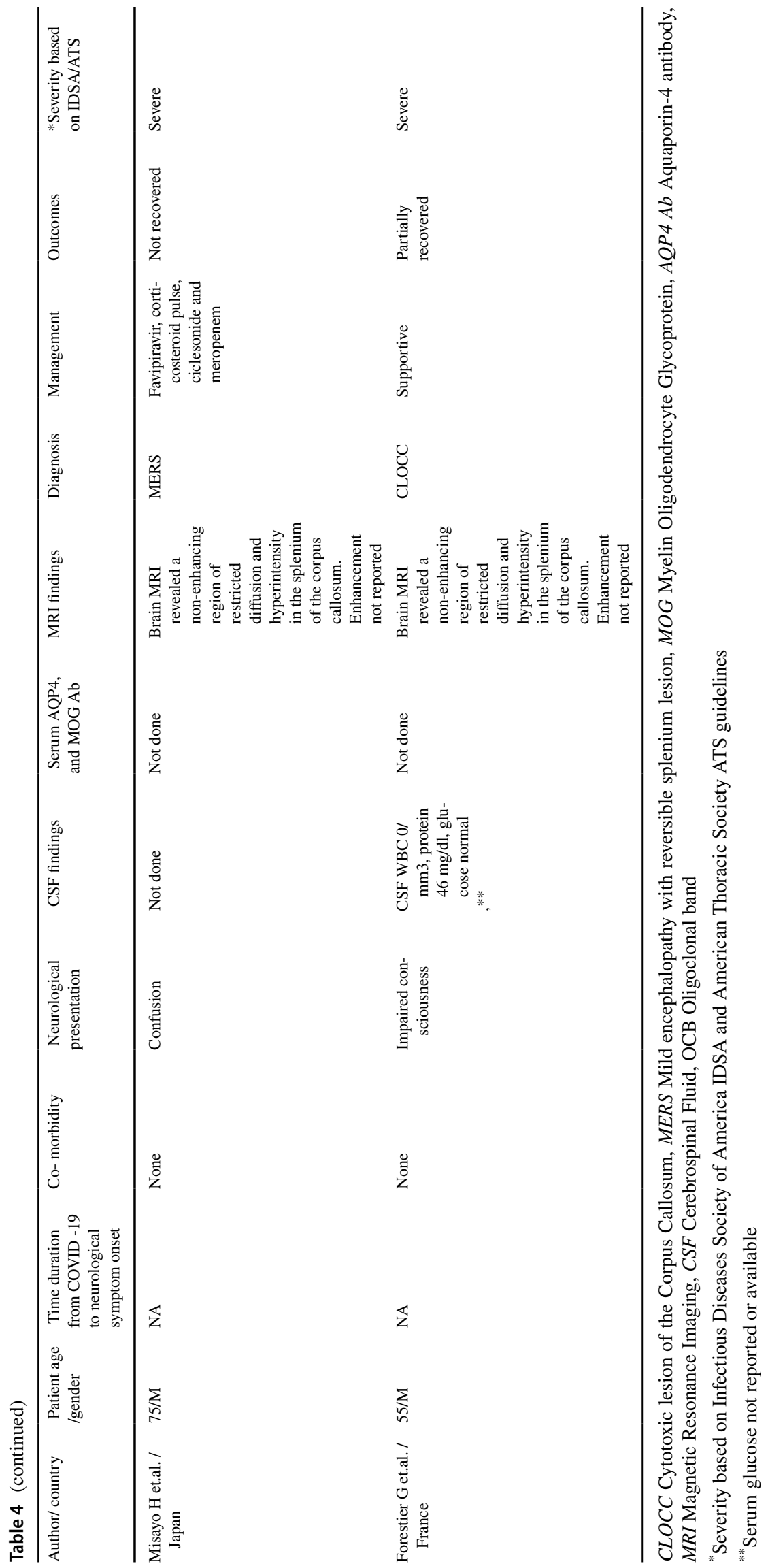


Table 5 General characteristics of SARS-CoV-2 patients with CNS inflammatory disorder $(n=40)$

\begin{tabular}{|c|c|}
\hline Characteristics & $N(\%)$ \\
\hline \multicolumn{2}{|l|}{ Age } \\
\hline Median (range), in years & $52.5(21-75)$ \\
\hline Mean (SD), in years & $50.7(15.1)$ \\
\hline Age $>50$ & $26(65)$ \\
\hline Age $\leq 50$ & $14(35)$ \\
\hline \multicolumn{2}{|l|}{ Gender } \\
\hline Male & $27(68)$ \\
\hline Female & $13(33)$ \\
\hline \multicolumn{2}{|l|}{ Clinical cohort } \\
\hline Transverse myelitis & $15(38)$ \\
\hline ADEM & $10(25)$ \\
\hline AHNE/AHLE & $6(15)$ \\
\hline CLOCC/MERS & $9(23)$ \\
\hline \multicolumn{2}{|l|}{ *Severity } \\
\hline Severe & $18(49)$ \\
\hline Non-severe & $19(51)$ \\
\hline \multicolumn{2}{|l|}{ \#Outcomes } \\
\hline Fatal & $7(19)$ \\
\hline Non-fatal & $29(81)$ \\
\hline \multicolumn{2}{|l|}{${ }^{\$}$ Treatment } \\
\hline IV Methylprednisolone & $25(71)$ \\
\hline IVIG & $9(26)$ \\
\hline PLEX & $8(23)$ \\
\hline Azithromycin & $2(6)$ \\
\hline Hydroxychloroquine & $3(9)$ \\
\hline Azithromycin + Hydroxychloroquine & $5(14)$ \\
\hline Remdesivir & $1(3)$ \\
\hline \multicolumn{2}{|l|}{ MRI abnormal enhancement } \\
\hline Abnormal enhancement of spinal cord on MRI & $4(10)$ \\
\hline Abnormal enhancement of brain on MRI & $9(23)$ \\
\hline
\end{tabular}

ADEM Acute Disseminated Encephalopathy, CLOCC Cytotoxic lesion of the Corpus Callosum, AHNE Acute Hemorrhagic Necrotizing Encephalopathy, AHLE Acute Hemorrhagic Leukoencephalopathy, IVIG Intravenous Immunoglobulin, PLEX Plasmapheresis, IVMP Intravenous Methylprednisolone, MRI Magnetic Resonance Imaging

* 3 cases severity data not available

\#4 cases outcome not available

$\$ 5$ cases treatment not available

the majority of the COVID-19 patients with neurological manifestations [58]. CSF cell count analysis was reported in 30 patients among which 11 cases had elevated cell count $>5$ cells $/ \mathrm{mm}^{3}$ with lymphocytic predominance.

\section{Acute myelitis including LETM plus optic neuritis}

Viral infections of the CNS are uncommon but are important in the differential diagnosis of acute/subacute myelopathy [59]. Acute myelitis was the most common CNS inflammatory disorder noted in our analysis with a total of 15 cases, including cases of TM and LETM. The average latency reported in previous cases of postinfectious myelitis/encephalomyelitis was 3-20 days $[11,60]$. The latency period of myelitis in this review was similar from less than 1 week $[22,23,26-28,33]$ to more than 1 week [25, 29-31, $36,37]$. The patients presented with a vast range of neurological symptoms, the most common in myelitis were urinary retention and lower limb weakness. Other less frequent symptoms were weakness in upper limb, quadriplegia; paresthesia of lower limb or upper limb or both. The MRI findings in myelitis were categorized into short segment $2(n=15,13.3 \%)$ as described by Chakraborty et. al. and Munz et al. [26, 30], or long segment cord involvement of either cervical, thoracic or cervico-thoracic reported in 12 cases [23, 25, 27-29, 31, 33-35]. Interestingly abnormal enhancement of spinal cord $(n=2,13.3 \%)$ was reported in two publications [23, 31]. Brain MRI studies were reported in 8 cases and were unremarkable in 7 cases [31-35]. One reported case had right pontine restriction diffusion ([36]. Zachariadis et al. reported normal spinal cord MRI in a 63-year-old man who presented with lower limb weakness and paresthesia where diagnosis for myelitis was based on clinical presentation and CSF elevated protein [32]. A case report by Zhao et al., did not have adequate investigations or their provided findings lacked essential data to fulfill all the inclusion criteria for diagnosis of acute myelitis [61].

Two cases of optic neuritis with positive serum Myelin oligodendrocytes glycoprotein (MOG) antibodies one of whom also had myelitis (MOGAD NMO) were reported by Zhou et al. and Sawalah et al. with MOG antibody titers of $1: 1000$ and 1:160 respectively with negative serum aquaporin 4 (AQP4) antibodies(Table 2). MOG is a protein expressed in the oligodendrocyte membrane and the outermost layer of myelin sheath. Antibodies against MOG have been involved in the pathogenesis of several neurological conditions as noted in subgroups of patients with ADEM, aquaporin-4 (AQP4) seronegative neuromyelitis optica spectrum disorders (NMOSD), monophasic or recurrent isolated optic neuritis $(\mathrm{ON})$, transverse myelitis, atypical MS and ADEM [62]. The demyelination caused by MOG antibodies is attributed to encephalitogenic T cells, antibody-dependent cell toxicity (ADCC) and complement dependent cytotoxicity (CDC) and encephalitogenic T cells which cause blood brain barrier leakage, inflammation and demyelination [63, 64].

The case described by Domingues et al. 42 years woman patient presenting with hemisensory loss 3 weeks after testing positive for CSF SARS-CoV-2 by RT-PCR. A focal cervical cord lesion at C-6 was demonstrated and normal brain MRI. CSF oligoclonal bands were absent with normal CSF cell count and protein. Testing for MOG and AQP4 


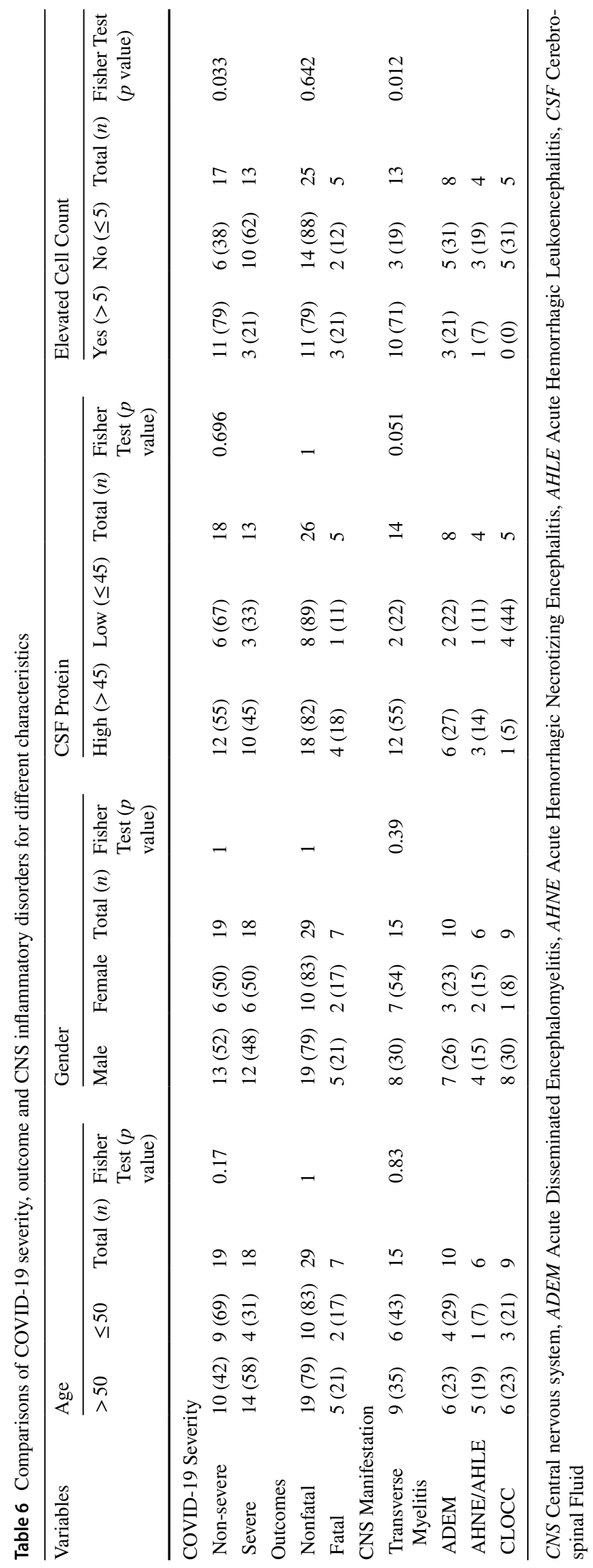


antibodies was not performed. This patient had an acute onset myelopathy, likely myelitis, of unknown cause. While described as case of suspected CNS demyelination as clinically isolated syndrome (CIS) the patient had a prior episode compatible with a cervical myelopathy and therefore might not meet strict criteria for CIS [65] (Table 2).

\section{ADEM including AHNE/ANLE}

ADEM is an immune-mediated generally, monophasic demyelinating disorder involving the brain and occasionally spinal cord. A number of infectious agents, mainly viruses, have been associated with ADEM [66]. In ADEM, latency periods typically vary from 0 days to 8 weeks [43]. The most common presentations were decreased responsiveness, limb weakness, paresthesia of lower limbs, and urinary retention. The most common finding seen on MRI was hyperintensity and restriction diffusion in the deep cerebral white matter. A peculiar finding of hemorrhages and hyperintense lesions within the subcortical and deep white matter of the frontoparietal lobes was noted by Langley et al. [41] and post autopsy findings of hemorrhagic white matter lesions throughout the cerebral hemispheres with surrounding axonal injury and macrophages by Reichard et al. [67]. The MRI findings of spinal cord involvement were of particular interest in 3 cases. The Zoghi et al. reported longitudinally extensive acute transverse myelitis in the thoracic and cervical segments, while Utukuri et al. reported the presence of mild $\mathrm{T} 2$ hyperintensities with minimal foci of non-enhancing T2 hyperintense lesions throughout the cervical and thoracic spinal cord. Novi et al. noted a single spinal cord lesion at T8 with bilateral optic nerve enhancement [21, 41, 42] (Table 3).

Acute necrotizing encephalopathy is a rare complication of influenza and other viral infections and has been related to intracranial cytokine storms, which result in blood-brain barrier breakdown but without direct viral invasion or parainfectious demyelination [68-71]. The similar and overlapping AHLE, which also includes demyelination, can be considered part of a continuum with ADEM based on clinical, pathologic and experimental evidence $[67,72,73]$. Our review revealed six cases of AHNE/AHLE associated with COVID-19. MRI findings in these cases included hyperintense T2 lesions in the thalami, cerebellum, brainstem, supratentorial gray and white matters without gadoliniumenhanced lesions with areas of restricted diffusion and microhemorrhage (Table 3 ). The patients predominately presented with decreased level of responsiveness. MRI findings showed hemorrhagic lesion lesions in bilateral thalami, medial temporal lobe and sub insular regions [52-57]. Outcome and severity of COVID-19 were not reported in one case [52] but the other 5 cases had severe COVID-19 based on IDSA/ATS guidelines [53-57]. There was two fatal outcome as reported by Dixon et al. $[53,56]$.

\section{CLOCC/MERS}

Cytotoxic lesions of the corpus callosum (CLOCC) is a disease entity associated with reversible lesions in the corpus callosum on MRI [74]. The MRI lesions typically resolve within a few days to weeks however the clinical recovery may take longer usually several months [75]. Our review noted 9 cases of CLOCC/MERS in patients with COVID19[44-51]. The patients had a varied range of clinical presentations, of which the most common was altered sensorium $(n=8)$, aphasia $(n=2)$, bradyphrenia $(n=1)$ and limb weakness $(n=1)$. MRI imaging in CLOCC demonstrated diffusion restriction and non-enhancing lesions mainly in the splenium of corpus callosum with variable involvement of remaining corpus callosum and cerebral white matter as noted in our cases as well (Table 4).

Our review has several limitations. Cases included in this review were identified through a comprehensive search of databases using a systematic search strategy. However, despite the set criteria, there is a possibility of missing out new upcoming reports and studies because of the evolving nature of the COVID-19 pandemic. A second limitation associated with any review is the concern that a disproportionate number of acute myelitis and other inflammatory neurological disorders associated with COVID are more likely to be reported in case reports and series which can introduce a bias. With the rapidly growing evidence of COVID-19 and association with neurological disorders, case reports and series of atypical demyelination disorders are more likely to be published. Finally, because of the emerging nature of the pandemic, there are no suitable contemporary non-COVID-19 case studies from the institutions reporting the COVID-19 associated CNS inflammatory variants, which would be the appropriate control for comparing the differences in clinical presentations, outcomes and pathophysiology of these disorders when not associated with COVID-19. We believe further studies and reviews are warranted.

\section{Conclusion}

In this paper we have reviewed and discussed the clinical features, neuroimaging, CSF findings and outcomes in patients with various manifestations of COVID-19 associated CNS inflammation. The most prevalent CNS inflammatory disorder was acute myelitis followed by ADEM including AHNE/AHLE variant and CLOCC respectively. Our review study reveals that CNS inflammatory disorders are rare but can be associated with COVID-19 infection as 
they have been reported with many other viruses. Further research using MRI imaging and CSF analysis in earlier diagnosis and intervention of these disorders is warranted.

Acknowledgements West Virginia Clinical and Translational Science Institute, Morgantown, WV, SW and SS supported in part by WVCTSI via US National Institute of General Medical Sciences of National Institute of Health under award under 5U54GM104942-05.

Author contributions Conceptualization: SS, MT, AP, RS Drafting the manuscript: SS, RL Data abstraction and data analysis: SP, SJ, ME, GG, SW, MK Editing and Final Draft: SS, RL.

Funding None.

Availability of data and materials Data was extracted from the articles published in PUBMED, Google Scholar, Scopus. This will be provided on request.

\section{Declarations}

Conflicts of interest In the last 2 years Dr. Lisak has participated as a speaker in meetings sponsored by and received consulting fees and/ or grant support from: Alexion, Argenx, UCB/Ra Pharmaceuticals, Novartis, Mallinckrodt, Genentech/Roche, Chugai, Janssen, GLG Consulting, Alpha Sites Consulting, Schlesinger Group Consulting, Slingshot Consulting, Health Sources, Adivo Associates, Smart Analyst, Clairview, Clarion and Decision Resources. He served as Chair of the Adjudication Committee for a MS clinical trial for MedDay (Biotin study). He is funded by a R21 grant by NINDS "Molecular Characterization of B Cell Exosomes in Multiple Sclerosis" and as site PI for NINDS funded study "LP4/Agrin Antibodies in Double Seronegative Myasthenia Gravis". He has received publication royalties from Oxford University Press (Neuroimmunology, 2019) and Blackwell Wiley (International Neurology, 2nd Edition, 2016). The rest of the authors have no disclosures.

\section{References}

1. WHO. WHO Coronavirus Disease (COVID-19) Dashboard. https://covid19. who.int/?gclid=Cj0KCQiA6t6ABhDMARIs AONIYywpPDg3HucQtbypR3MmCf9RzstxhVodEx73VZCfp bDuLfpNoy-73caAvp_EALw_wcB

2. Chowdhary A, Subedi R, Tandon M, Wen S, Patel J, Kataria $S$ et al (2020) Relevance and clinical significance of magnetic resonance imaging of neurological manifestations in COVID-19: a systematic review of case reports and case series. Brain Sci 10(12): 1017

3. Berger JR (2020) COVID-19 and the nervous system. J Neurovirol 26:143-148

4. Mao L, Jin H, Wang M, Hu Y, Chen S, He Q, Chang J, Hong C, Zhou Y, Wang D, Miao X (2020) Neurologicmanifestations of hospitalized patients with coronavirus disease 2019 in Wuhan, China. JAMA Neurol 77(6):683-690

5. Munhoz RP, Pedroso JL, Nascimento FA, Almeida SMd, Barsottini OGP, Cardoso FEC et al (2020) Neurological complications in patients with SARS-CoV-2 infection: a systematic review. Arq Neuropsiquiatr 78(5):290-300

6. Lechien JR, Chiesa-Estomba CM, De Siati DR, Horoi M, Le Bon SD, Rodriguez A, Dequanter D, Blecic S, El Afia F, Distinguin
L, Chekkoury-Idrissi Y (2020) Olfactory and gustatory dysfunctions as a clinical presentation of mild-to-moderate forms of the coronavirus disease (COVID-19): a multicenter European study. Euro Arch Oto Rhino Laryngol 277(8):2251-2261

7. Aragão MdFVV, Leal M, CartaxoFilho O, Fonseca T, Valença $M$ (2020) Anosmia in COVID-19 associated with injury to the olfactory bulbs evident on MRI. Am J Neuroradiol 41(9):1703-1706

8. Frontera JA, Sabadia S, Lalchan R, Fang T, Flusty B, MillarVernetti $\mathrm{P}$ et al (2021) A prospective study of neurologic disorders in hospitalized patients with COVID-19 in New York City. Neurology 96(4):e575-e586

9. Abolmaali M, Heidari M, Zeinali M, Moghaddam P, Ghamsari MR, Makiani MJ, Mirzaasgari Z (2021) Guillain-Barré syndrome as a parainfectious manifestation of SARS-CoV-2 infection: a case series. J Clin Neurosci 83:119-1122

10. Iadecola C, Anrather J, Kamel H (2020) Effects of COVID-19 on the nervous system. Cell 183(1):16-27

11. Marchioni E, Ravaglia S, Piccolo G, Furione M, Zardini E, Franciotta D et al (2005) Postinfectious inflammatory disorders: subgroups based on prospective follow-up. Neurology 65(7):1057-1065

12. Moher D, Liberati A, Tetzlaff J, Altman DG, The PRISMAG (2009) Preferred reporting items for systematic reviews and meta-analyses: the PRISMA statement. PLoS Med 6(7):e1000097

13. Joanna BI (2019) The Joanna Briggs Institute critical appraisal tools for use in JBI systematic review: checklists for case reports

14. Metlay JP, Waterer GW, Long AC, Anzueto A, Brozek J, Crothers $\mathrm{K}$ et al (2019) Diagnosis and treatment of adults with communityacquired pneumonia. An Official Clinical Practice Guideline of the American Thoracic Society and Infectious Diseases Society of America. Am J Respir Crit Care Med. 200(7):e45-e67

15. Sriwastava S, Kataria S, Tandon M, Patel J, Patel R, Jowkar A, Daimee M, Bernitsas E, Jaiswal P, Lisak RP (2020) Guillain Barré Syndrome and its variants as a manifestation of COVID19: a systemic review of case report and case series. J Neurol Sci 420:117263

16. Dalakas MC (2020) Guillain-Barre syndrome: the first documented COVID-19-triggered autoimmune neurologic disease: More to come with myositis in the offing. Neurol Neuroimmunol Neuroinflamm 7(5):e781

17. García-Sastre A, Biron CA (2006) Type 1 interferons and the virus-host relationship: a lesson in detente. Science 312(5775):879-882

18. Mehta P, McAuley DF, Brown M, Sanchez E, Tattersall RS, Manson JJ (2020) COVID-19: consider cytokine storm syndromes and immunosuppression. Lancet 395(10229): 1033-1034

19. Frohman EM, Racke MK, Raine CS (2006) Multiple sclerosisthe plaque and its pathogenesis. New Engl J Med 354(9):942-955

20. Gotkine M, Kennedy PG, Steiner I (2010) Post infectious CNS disorders: towards a unified approach. J Neurol 257(12):1963-1969

21. Zoghi A, Ramezani M, Roozbeh M, Darazam IA, Sahraian MA (2020) A case of possible atypical demyelinating event of the central nervous system following COVID-19. Mult Scler Relat Disord 44:102324

22. Baghbanian SM, Namazi F (2020) Post COVID-19 longitudinally extensive transverse myelitis (LETM)-a case report. Acta Neurol Belgica 18:1-2

23. Sarma D, Bilello LA (2020) A case report of acute transverse myelitis following novel coronavirus infection. Clin Pract Cases Emer Med 4(3):321

24. Zhao K, Huang J, Dai D, Feng Y, Liu L, Nie S (2020) Acute myelitis after SARS-CoV-2 infection: a case report. MedRxiv. https://doi.org/10.21203/rs.3.rs-68798/v1 
25. Chow CA-O, Magnussen J, Ip J, Su YA-O (2020) Acute transverse myelitis in COVID-19 infection. LID. https://doi.org/10. 1136/bcr-2020-236720

26. Chakraborty U, Chandra AA-O, Ray AK, Biswas P (2020) COVID-19-associated acute transverse myelitis: a rare entity. LID. https://doi.org/10.1136/bcr-2020-238668

27. Valiuddin H, Skwirsk B, Paz-Arabo P (2020) Acute transverse myelitis associated with SARS-CoV-2: a case-report. Brain Behav Immun Health. https://doi.org/10.1016/j.bbih.2020.100091

28. AlKetbi R, AlNuaimi D, AlMulla M, AlTalai N, Samir M, Kumar $\mathrm{N}$ et al (2020) Acute myelitis as a neurological complication of Covid-19: a case report and MRI findings. Radiol Case Rep 15(9):1591-1595

29. Durrani M, Kucharski K, Smith Z, Fien S (2020) Acute transverse myelitis secondary to severe acute respiratory syndrome coronavirus 2 (SARS-CoV-2): a case report. Clin Pract Cases Emer Med 4(3):344

30. Munz M, Wessendorf S, Koretsis G, Tewald F, Baegi R, Krämer S, Geissler M, Reinhard M (2020) Acute transverse myelitis after COVID-19 pneumonia. J Neurol 267:2196-2197

31. Sotoca J, Rodríguez-Álvarez Y (2020) COVID-19-associated acute necrotizing myelitis. Neurol Neuroimmunol Neuroinflamm 7(5):e803

32. Zachariadis A, Tulbu A, Strambo D, Dumoulin A, Di Virgilio G (2020) Transverse myelitis related to COVID-19 infection. J Neurol 267(12):3459-3461

33. Abdelhady M, Elsotouhy A, Vattoth S (2020) Acute flaccid myelitis in COVID-19. BJRI Case Rep 6(3):20200098

34. Lisnic V, Nemtan V, Hacina E, Topciu G, Manole E, Thurnher MM, von Kummer R. Acute transverse myelitis in a HIVpositive patient with COVID-19. https://doi.org/10.21203/rs.3. rs-50901/v1

35. Escobar MM, Kataria S, Khan E, Subedi R, Tandon M, Peshwe $\mathrm{K}$ et al (2021) Acute transverse myelitis with Dysautonomia following SARS-CoV-2 infection: a case report and review of literature. J Neuroimmunol 2021:577523

36. Memon AB, Al-Hader R, Patel S, Malik S, Megally M, Steijlen KL et al (2021) Late-onset rapidly progressive MRI- negative-myelitis after COVID-19 illness. Clin Neurol Neurosurg 202:106513

37. Fumery T, Baudar C, Ossemann M, London F (2021) Longitudinally extensive transverse myelitis following acute COVID-19 infection. Mult Scler Relat Disord. 48:102723

38. McCuddy M, Kelkar P, Zhao Y, Wicklund D (2020) Acute demyelinating encephalomyelitis (ADEM) in COVID-19 infection: a case series. medRxiv

39. Parsons T, Banks S, Bae C, Gelber J, Alahmadi H, Tichauer M (2020) COVID-19-associated acute disseminated encephalomyelitis (ADEM). J Neurol 267:2799-2802

40. Assunção FB, Fragoso DC, Scoppetta TD, Maia AM (2020) COVID-19-associated acute disseminated encephalomyelitis-like disease. Am J Neuroradiol. https://doi.org/10.1007/ s00415-020-09951-9

41. Novi G, Rossi T, Pedemonte E, Saitta L, Rolla C, Roccatagliata L, Inglese M, Farinini D (2020) Acute disseminated encephalomyelitis after SARS-CoV-2 infection. Neurol Neuroimmunol Neuroinflamm 7(5):e797

42. Utukuri PS, Bautista A, Lignelli A, Moonis G (2020) Possible acute disseminated encephalomyelitis related to severe acute respiratory syndrome coronavirus 2 infection. Am J Neuroradiol 41(9):E82-E83

43. Langley L, Zeicu C, Whitton L, Pauls M (2020) Acute disseminated encephalomyelitis (ADEM) associated with COVID-19. BMJ Case Reports CP 13(12):e239597
44. Rasmussen C, Niculescu I, Patel S, Krishnan A (2020) COVID19 and involvement of the corpus callosum: potential effect of the cytokine storm? Am J Neuroradiol 41(9):1625-1628

45. Elkhaled W, Abid FB, Akhtar N, Abukamar MR, Ibrahim WH (2020) A 23-year-old man with SARS-CoV-2 infection who presented with auditory hallucinations and imaging findings of cytotoxic lesions of the corpus callosum (CLOCC). Am J Case Rep 21:e928798-e928801

46. Agarwal N, Martini R, Pedrotti G, Della SSW (2020) Unusual lesion in the splenium of the corpus callosum and coronavirus infectious disease-19. BJRICase Rep 6(3):20200068

47. Moreau A, Ego A, Vandergheynst F, Taccone FS, Sadeghi N, Montesinos I, Gaspard N, Gorham J (2020) Cytotoxic lesions of the corpus callosum (CLOCCs) associated with SARS-CoV-2 infection. J Neurol 68(5):1592-1594

48. Edjlali M, Le Gal A, Louvet M, Matt M, Leveque C, Diffre C et al (2020) Teaching NeuroImages: cytotoxic lesions of the corpus callosum in encephalopathic patients with COVID-19. Neurology 95(22):1021-1022

49. Kakadia B, Ahmed J, Siegal T, Jovin TG, Thon JM (2020) Mild encephalopathy with reversible splenium lesion (MERS) in a patient with COVID-19. J Clin Neurosci 79:272-274

50. Hayashi M, Sahashi Y, Baba Y, Okura H, Shimohata T (2020) COVID-19-associated mild encephalitis/encephalopathy with a reversible splenial lesion. J Neurol Sci 415:116941

51. Forestier G, de Beaurepaire I, Bornet G, Boulouis G (2020) Cytotoxic lesion of the corpus callosum as presenting neuroradiological manifestation of COVID-2019 infection. J Neurol 268(5):1595-1597

52. Poyiadji N, Shahin G, Noujaim D, Stone M, Patel S, Griffith B (2020) COVID-19-associated acute hemorrhagic necrotizing encephalopathy: imaging features. Radiology 296(2):E119-E120

53. Dixon L, Varley J, Gontsarova A, Mallon D, Tona F, Muir D, Luqmani A, Jenkins IH, Nicholas R, Jones B, Everitt A (2020) COVID-19-related acute necrotizing encephalopathy with brain stem involvement in a patient with aplastic anemia. Neurol Neuroimmunol Neuroinflamm 7(5)

54. Delamarre L, Gollion C, Grouteau G, Rousset D, Jimena G, Roustan J et al (2020) COVID-19-associated acute necrotising encephalopathy successfully treated with steroids and polyvalent immunoglobulin with unusual IgG targeting the cerebral fibre network. J Neurol Neurosurg Psychiatry 91(9):1004-1006

55. Yong MH, Chan YFZ, Liu J, Sanamandra SK, Kheok SW, Lim KC et al (2020) A Rare Case of Acute Hemorrhagic Leukoencephalitis in a COVID-19 Patient. J Neurol Sci 416:117035

56. Varadan B, Shankar A, Rajakumar A, Subramanian S, Sathya AC, Hakeem AR, Kalyanasundaram S (2021) Acute hemorrhagic leukoencephalitis in a COVID-19 patient-a case report with literature review. Neuroradiology 63(5):653-661

57. Haqiqi A, Samuels TL, Lamb FJ, Moharrum T, Myers AE (2021) Acute haemorrhagic leukoencephalitis (Hurst disease) in severe COVID- 19 infection. Brain Behav Immunity Health 12:100208

58. Tandon M, Kataria S, Patel J, Mehta TR, Daimee M, Patel V, Prasad A, Chowdhary AA, Jaiswal S, Sriwastava S (2021) A comprehensive systematic review of csf analysis that defines neurological manifestations of COVID-19. Int J Infect Diseases 104:390-397

59. Kincaid O, Lipton HL (2006) Viral myelitis: an update. Curr Neurol Neurosci Rep 6(6):469

60. Chang CM, Ng HK, Chan YW, Leung SY, Fong KY, Yu YL (1992) Postinfectious myelitis, encephalitis and encephalomyelitis. Clin Exp Neurol 29:250-262

61. Transverse Myelitis Consortium Working Group* (2002) Proposed diagnostic criteria and nosology of acute transverse myelitis. Neurology 59(4):499-505 
62. Peschl P, Bradl M, Höftberger R, Berger T, Reindl M (2017) Myelin oligodendrocyte glycoprotein: deciphering a target in inflammatory demyelinating diseases. Front Immunol 8:529

63. Peschl P, Schanda K, Zeka B, Given K, Böhm D, Ruprecht K, Saiz A, Lutterotti A, Rostásy K, Höftberger R, Berger T (2017) Human antibodies against the myelin oligodendrocyte glycoprotein can cause complement-dependent demyelination. J Neuroinflamm 14(1):1-4

64. Dale RC, Tantsis EM, Merheb V, Kumaran RY, Sinmaz N, Pathmanandavel K, Ramanathan S, Booth DR, Wienholt LA, Prelog K, Clark DR (2014) Antibodies to MOG have a demyelination phenotype and affect oligodendrocyte cytoskeleton. Neurol Neuroimmunol Neuroinflamm 1(1):e12

65. Domingues RB, Mendes-Correa MC, de Moura Leite FB, Sabino EC, Salarini DZ, Claro I, Santos DW, de Jesus JG, Ferreira NE, Romano CM, Soares CA (2020) First case of SARS-COV-2 sequencing in cerebrospinal fluid of a patient with suspected demyelinating disease. J Neurol 267(11):3154-3156

66. Menge T, Hemmer B, Nessler S, Wiendl H, Neuhaus O, Hartung HP, Kieseier BC, Stüve O (2005) Acute disseminated encephalomyelitis: an update. Arch Neurol 62(11):1673-1680

67. Reichard RR, Kashani KB, Boire NA, Constantopoulos E, Guo Y, Lucchinetti CF (2020) Neuropathology of COVID-19: a spectrum of vascular and acute disseminated encephalomyelitis (ADEM)like pathology. Acta Neuropathol 140(1):1-6
68. Wong AM, Simon EM, Zimmerman RA, Wang HS, Toh CH, Ng SH (2006) Acute necrotizing encephalopathy of childhood: correlation of MR findings and clinical outcome. Am J Neuroradiol 27(9):1919-1923

69. Rossi A (2008) Imaging of acute disseminated encephalomyelitis. Neuroimaging Clin N Am 18(1):149-161

70. Offiah C, Hall E (2013) Acute necrotizing encephalopathy associated with novel influenza H1N1 (pdm09) infection: MRI and correlation with brain necropsy. J Pediatric Neuroradiol 2(4):319-324

71. Mizuguchi M (1997) Acute necrotizing encephalopathy of childhood: a novel form of acute encephalopathy prevalent in Japan and Taiwan. Brain Develop 19(2):81-92

72. Russell DS (1955) The nosological unity of acute haemorrhagic leucoencephalitis and acute disseminated encephalomyelitis. Brain 78(3):369-376

73. Behan PO, Kies MW, Lisak RP, Sheremata W, Lamarche JB (1973) Immunologic mechanisms in experimental encephalomyelitis in nonhuman primates. Arch Neurol 29(1):4-9

74. Starkey J, Kobayashi N, Numaguchi Y, Moritani T (2017) Cytotoxic lesions of the corpus callosum that show restricted diffusion: mechanisms, causes, and manifestations. Radiographics. 37(2):562-576

75. Tetsuka S (2019) Reversible lesion in the splenium of the corpus callosum. Brain Behav 9(11):e01440-e 